\title{
Nuclear Wiskott-Aldrich syndrome protein co-regulates T cell factor 1-mediated transcription in T cells
}

\author{
Nikolai V. Kuznetsov', Bader Almuzzaini ${ }^{2,3}$, Joanna S. Kritikou', Marisa A. P. Baptista ${ }^{1,4}$, Mariana M. S. Oliveira', \\ Marton Keszei ${ }^{1}$, Scott B. Snapper ${ }^{5}$, Piergiorgio Percipalle ${ }^{2,6,7}$ and Lisa S. Westerberg ${ }^{1^{*}}$
}

\begin{abstract}
Background: The Wiskott-Aldrich syndrome protein (WASp) family of actin-nucleating factors are present in the cytoplasm and in the nucleus. The role of nuclear WASp for T cell development remains incompletely defined.

Methods: We performed WASp chromatin immunoprecipitation and deep sequencing (ChIP-seq) in thymocytes and spleen $\mathrm{CD}^{+} \mathrm{T}$ cells.

Results: WASp was enriched at genic and intergenic regions and associated with the transcription start sites of protein-coding genes. Thymocytes and spleen $\mathrm{CD}^{+} \mathrm{T}$ cells showed 15 common WASp-interacting genes, including the gene encoding T cell factor (TCF)12. WASp KO thymocytes had reduced nuclear TCF12 whereas thymocytes expressing constitutively active WASP ${ }^{\text {L272P }}$ and WASp ${ }^{1296 T}$ had increased nuclear TCF 12 , suggesting that regulated WASp activity controlled nuclear TCF12. We identify a putative DNA element enriched in WASp ChIP-seg samples identical to a TCF1-binding site and we show that WASp directly interacted with TCF1 in the nucleus.
\end{abstract}

Conclusions: These data place nuclear WASp in proximity with TCF1 and TCF12, essential factors for T cell development.

Keywords: WASp, T cells, ChIP-seq, Wiskott-Aldrich syndrome, TCF1, TCF12, Nucleus

\section{Background}

The actin cytoskeleton is essential for life and regulates critical cellular functions including morphogenesis, migration, cytokinesis, membrane transport, and cell-tocell communication.

In addition to its fundamental role in the cytoplasm, actin resides in the nucleus and regulates chromatin remodeling, RNA processing, and nucleoskeletal stability and transcription [1]. Nuclear actin serves multiple functions, both dependent and independent, on its role in polymerization of actin filaments [2-5]. Spontaneous actin assembly is inefficient and the cell uses a number of actin nucleating promoting factors to obtain rapid and dynamic actin polymerization [6]. The Wiskott-Aldrich syndrome (WASp) family of nucleating promoting

\footnotetext{
* Correspondence: Lisa.Westerberg@ki.se

'Department of Microbiology Tumor and Cell biology, Karolinska Institutet, Stockholm 171 77, Sweden

Full list of author information is available at the end of the article
}

factors all contain a verprolin-cofilin-acidic (VCA) domain that binds to the actin-related protein (Arp) $2 / 3$ complex to induce actin polymerization leading to formation of branched filaments [6]. It has become increasingly clear that actin nucleating promoting factors such as the WASp family are present both in the cytoplasm and in the nucleus. The WASp family of proteins includes WASp, neuronal (N)-WASp, and WASp-family verprolin-homologous protein (WAVE)/suppressor of the cyclic AMP receptor (SCAR) 1-3, WASp and SCAR homologue (WASH), and junction-mediating and regulatory protein (JMY) [7]. The activity of WASp, NWASp, and WAVE/SCAR 1-3 are regulated by the Rho family GTPases Cdc42, Rac1, and Rac2. At rest, WASp and N-WASp resides in an auto-inhibited conformation due to an intramolecular interaction between the VCA domain and the GTPase-binding domain. Upon binding of Cdc42, the auto-inhibited conformation is released and exposes the VCA domain that allows for recruitment 
of the Arp2/3 complex and actin polymerization [8-10]. Rac1 and Rac2 regulate activation of the multimeric WAVE/Scar regulatory complex to stimulate actin polymerization by the VCA domain [11-13].

All steps of $\mathrm{T}$ cell development in thymus is coordinated by the actin cytoskeleton to control cycles of $\mathrm{T}$ cell migration and stable immunological synapse assembly with antigen-presenting stroma cells and dendritic cells [14]. Moreover, the development of T cells from multipotent progenitor cells depends on fine-tuned regulation of transcription factors (TFs), resulting in the loss of alternative lineage potential and the acquisition of the $\mathrm{T}$ cell functional identity. This lineage commitment relies on Notch signaling and the activity of TFs such as the high mobility group (HMG) family of TFs $\mathrm{T}$ cell factor (TCF)1, lymphoid enhancer factor (Lef)1, and the E-box proteins TCF12/HeLa E-box-binding protein (HEB), E22 , and E2A $[15,16]$. In thymus, T cells develop from $\mathrm{CD} 4^{-} \mathrm{CD}^{-}$double-negative thymocytes to express a functional $\mathrm{T}$ cell receptor (TCR) upon which they become $\mathrm{CD}_{4}^{+} \mathrm{CD}^{+}$double-positive thymocytes. The $\mathrm{CD} 4$ ${ }^{+} \mathrm{CD}^{+}$double-positive thymocytes constitute more than $80 \%$ of all cells in the thymus and develop into CD4 ${ }^{+} \mathrm{CD} 8^{-}$and $\mathrm{CD} 4^{-} \mathrm{CD}^{+}$single-positive $\mathrm{T}$ cells that leaves the thymus and enter into the circulation as mature $\mathrm{CD} 4^{+}$and $\mathrm{CD}^{+}{ }^{+}$cells.

WASp is uniquely expressed in hematopoietic cells and its role for their normal function have been extensively studied in Wiskott-Aldrich syndrome (WAS) patients that lack expression of WASp and in genetargeted mice (WASp KO mice) $[17,18]$. These studies have revealed WASp to be critical for correct $\mathrm{T}$ cell function and $40-70 \%$ of WAS patients develop $\mathrm{T}$ cellmediated autoimmunity [17-22]. This could at least in part be due to a limited and more autoreactive T cell receptor repertoire in peripheral blood T cells from WAS patients [23-26] and in thymocytes and spleen $\mathrm{T}$ cells from WASp KO mice [27]. WASp KO thymocytes and $\mathrm{T}$ cells show decreased proliferation in response to $\mathrm{T}$ cell receptor stimulation [21, 28, 29] and this is associated with reduced translocation of nuclear factor of activated $\mathrm{T}$ cells (Nfatc) 2 into the nucleus of WASp KO T cells upon $\mathrm{T}$ cell receptor stimulation, leading to decreased expression of interleukin-2 [30-32]. X-linked neutropenia (XLN) is a more recently described WASpassociated disease caused by point mutations $\left(\mathrm{WASp}^{\mathrm{L} 270 \mathrm{P}}, \mathrm{WASp}^{\mathrm{S} 272 \mathrm{P}}, \mathrm{WASp}^{\mathrm{I} 276 \mathrm{~S}}\right.$, and $\mathrm{WASp}^{\mathrm{I} 294 \mathrm{~T}}$ ) in the WASp GTPase-binding domain that renders WASp constitutively active by destroying the autoinhibited folding of WASp [33-37]. Murine spleen T cells expressing $\mathrm{WASp}^{\mathrm{L} 272 \mathrm{P}}$ and WASp ${ }^{\mathrm{I} 296 \mathrm{~T}}$ (corresponding to human WASp $^{\text {L270P }}$ and WASp ${ }^{\mathrm{I} 294 \mathrm{~T}}$ ) have an increased load of polymerized actin associated with decreased cell spreading [37].
Using a chromatin immunoprecipitation (ChIP) on array approach including 50 genes known to regulate $\mathrm{T}$ helper (Th)1 and Th2 commitment, Vyas et al. showed that nuclear WASp in peripheral blood $\mathrm{T}$ cells interacts specifically with Tbx12-induced genes for Th1 commitment [38]. Moreover, using in vitro derived Th1 cells, WASp interacts with a subset of SWItch/Sucrose Non-Fermentable (SWI/SNF) complexes to drive transcription of Tbx12-induced genes [39]. Other interaction partners of WASp in the nucleus remain to be identified. Although WASp has been extensively investigated in proximity to $\mathrm{T}$ cell receptor signaling in the cytoplasm, the role of nuclear WASp for $\mathrm{T}$ cell development remains to be identified and should be important to fully understand the pathophysiology of WASp-associated immunodeficiency diseases.

To identify the global gene occupancy by WASp in the nucleus during $\mathrm{T}$ cell development, we took the unbiased approach to perform ChIP sequencing (ChIP-seq) and compare thymocytes (immature T cells) and spleen $\mathrm{CD}^{+} \mathrm{T}$ cells (mature $\mathrm{T}$ cells). We identify 15 common WASp-enriched genes, including the gene encoding for TCF12. By comparing wild type (WT), WASp KO, WASp $^{\text {L272P }}$, and WASp ${ }^{\text {I296T }}$ thymocytes from genetargeted mice, our data show that the activation status of WASp affects TCF12 protein in the nucleus. We identify a putative WASp DNA-binding site identical to the TCF1-binding site and we show that WASp interacted with TCF1 in the nucleus. Together, we define that nuclear WASp acts in proximity with TCF1 and TCF12, important for normal $\mathrm{T}$ cell development.

\section{Methods \\ Mice}

WASp ${ }^{\mathrm{L} 272 \mathrm{P}}$ mice (C57Bl/6 ES cells, C57Bl/6 background) and WASp ${ }^{\text {I296T }}$ mice (mixed $129 \mathrm{~Sv}$ and C57Bl/ 6 ES cells, backcrossed for eight generations to C57Bl/6 background) were generated by insertion of a point mutation into germline WASp exon 9; TTG to CCG to generate the Leu-272 to Pro-272 knock-in mutation or ATT to ACT to generate the Iso-296 to Thr-296. The WASp $^{\text {L272P }}$ and WASp ${ }^{\text {I296T }}$ knock in strains were generated by Ingenious Targeting Laboratory. WASp KO (C57Bl/6 background) [40], WASp ${ }^{\mathrm{L} 272 \mathrm{P}}, \mathrm{WASp}^{\mathrm{I} 296 \mathrm{~T}}$, and littermate age- and sex-matched WT mice were bred and maintained at the animal facility of the Department of Microbiology, Tumor and Cell Biology at Karolinska Institutet under specific pathogen-free conditions. Males were used at six weeks of age and all animal experiments were performed after approval from the local ethical committee (the north Stockholm district court); protocol approval number: N77/13. 


\section{Mouse primary cells and cell cultures}

WT, WASp KO, WASp ${ }^{\text {L272P }}$, and WASp ${ }^{\text {I296T }}$ thymocytes were isolated by thymi homogenization through $100-\mu \mathrm{m}$ strainers (Corning) and cell resuspension in sterile cold $1 \mathrm{x}$ PBS. Ten thymi of a specific genotype were pooled and used per ChIP experiment. WT, WASp KO, WASp ${ }^{\text {L272P, }}$ and $\mathrm{WASp}^{\text {I296T }} \mathrm{CD}^{+} \mathrm{T}$ cells were isolated by spleen homogenization through $100 \mu \mathrm{m}$ strainers (Corning) followed by splenocytes-derived T cell isolation using CD4 ${ }^{+} \mathrm{T}$ Cell Isolation Kit (Miltenyi). The purity of $\mathrm{CD}^{+} \mathrm{CD}^{+}$ T cells was 94-96\% (Additional file 1: Figure S1). Cell lines used: murine fibroblast L-cells (ATCC no. CRL-2648) and A20 (mouse reticulum cell sarcoma lymphoblast lymphoblastoma) cell line (ATCC no. TIB-208). Experiments that were from different biological samples (cells or mice) and performed at least twice and consistently measured are considered biological replicates. Consistent measurements of one biological sample performed at least twice are considered technical replicates.

\section{Cell fractionation and immunoprecipitation (IP)}

Mouse thymi were collected and cell suspension prepared with the use of $100-\mu \mathrm{m}$ strainers (Corning). For cell fractionation, the Nuclear/Cytosol Fractionation Kit \#K266-25 (BioVision) was used. For IP, a protease inhibitors cocktail (SigmaAldrich) was added to all buffers and lysis solutions. $10^{8}$ cells $/ \mathrm{mL}$ were washed twice with cold $1 \mathrm{x}$ PBS containing a protease inhibitors cocktail (Sigma-Aldrich), sedimented in Eppendorf centrifuge $\left(2000 \mathrm{rpm}, 5 \mathrm{~min}, 4^{\circ}\right.$ C). Total cell lysates were prepared by incubation on ice for $30 \mathrm{~min}$ of the cell pellet in equal volume of lysis buffer containing NP-40, followed by centrifugation $(14,000 \mathrm{rpm}$, $\left.15 \mathrm{~min}, 4{ }^{\circ} \mathrm{C}\right)$. Supernatants were collected and precleared by adding $100 \mu \mathrm{L}$ of pre-equilibrated rec-Protein G-Sepharose $\mathrm{e}^{\curvearrowleft} \mathrm{B}$ Conjugate (Invitrogen) suspension per sample. Ten to $20 \mu \mathrm{L}$ of antibodies were added to precleared supernatant and immunoprecipitation performed during $10 \mathrm{~h}$ at $4{ }^{\circ} \mathrm{C}$ on shaking platform. Afterwards, $100 \mu \mathrm{L}$ of pre-equilibrated protein G-Sepharose beads suspension per sample was added to the IP samples with continued incubation during $4 \mathrm{~h}$ at $4{ }^{\circ} \mathrm{C}$ on shaking platform. Triple wash of IP samples was performed via beads resuspension in $1 \mathrm{~mL}$ of cold $1 \mathrm{x}$ PBS followed by centrifugation (1000 rpm, $3 \mathrm{~min}$, at $4{ }^{\circ} \mathrm{C}$ ) and collection of supernatant. One hundred microliter aliquots of loading and three washes were collected and stored frozen at $-20{ }^{\circ} \mathrm{C}$. Bead pellets were re-suspended in $300 \mu \mathrm{L}$ of $4 \mathrm{x}$ Laemmli gel loading buffer. Samples were heated at $95{ }^{\circ} \mathrm{C}$ in a solid block thermostat for $10 \mathrm{~min}$ and centrifuged $(1500 \mathrm{rpm}$, $5 \mathrm{~min}$, room temperature). Collected supernatant aliquots were stored at $-20{ }^{\circ} \mathrm{C}$ and used for western blotting analysis as described. Ten to $20 \mu \mathrm{L}$ of purified mouse $\operatorname{IgG}_{2 \mathrm{~A}}$ (\#401501, Biolegend) was used as the isotype antibody (Ab)-negative control in co-IP experiment.

\section{Chromatin immunoprecipitation (ChIP)}

Three rounds of sample preparation for ChIP-seq were made. (1) High stringency condition was used for ChIP of WT thymocytes with the WASp Ab or an isotype control. Only the WASp ChIP sample could be used for sequencing since the isotype control sample had too low DNA concentration by Bioanalyzer analysis for sequencing (Additional file 1: Figure S2B). (2) To obtain enough DNA for sequencing, the WT spleen $\mathrm{CD}^{+}{ }^{+} \mathrm{T}$ cell sample was prepared under low stringency for WASp ChIP (Additional file 1: Figure S2C). An Ab-free WT spleen-negative control sample was sequenced and all hits present in this sample were subtracted from the WASp ChIP-seq data of the WT spleen CD4 ${ }^{+} \mathrm{T}$ cells (Fig. 1c). (3) ChIP samples from WT, WASp ${ }^{\text {I296T }}$, and WASp KO thymocytes were prepared under low stringency. The WASp KO thymocyte sample had too low DNA concentration by Bioanalyzer for sequencing (Additional file 1: Figure S2D). To detect differential DNA interaction between WASp ${ }^{\text {I296T }}$ and WT WASp, we removed all similar hits between the two samples to identify the unique genome occupancy by WASp ${ }^{\text {I296T }}$. The ChIP protocol was performed with high stringency or low stringency in regard to fixation and washing conditions. Two milliliters of single-cell suspension per ChIP sample containing $1-2 \times 10^{8}$ cells were used. For high stringency, cells were cross-linked with $1 \%$ FA for $15 \mathrm{~min}$, and for low stringency, cells were cross-linked with $10 \mathrm{mM}$ DMA (linker arm length $8.6 \AA$, Pierce) for $1 \mathrm{~h} \pm 0.75 \%$ FA for $5 \mathrm{~min}$. Cross-linking was followed by a 20-min incubation with $137 \mathrm{mM}$ glycine to quench the formaldehyde cross-linking. Cells were washed twice with cold $1 \mathrm{x}$ PBS, harvested by centrifugation, resuspended in $1 \mathrm{x}$ PBS, and briefly sonicated on ice using Bioruptor UCD-200 sonication system (Diagenode) at a setting of 5 for 30-s pulses with a 30-s pause between pulses. Cell lysates were treated with $100 \mathrm{U} / \mathrm{mL}$ benzonase (Merck) for $40 \mathrm{~min}$ at room temperature with slow rotation and the nuclease reaction was stopped by addition of EDTA to a final concentration of $5 \mathrm{mM}$. After quenching of the benzonase reaction, the samples were centrifuged at $20,000 \mathrm{~g}$ for $15 \mathrm{~min}$ at $4{ }^{\circ} \mathrm{C}$. The supernatant was collected and $10 \%$ (volume) of the supernatant was stored $\left(-20{ }^{\circ} \mathrm{C}\right)$ for further ChIP-seq input control DNA analysis. Ten microliters of monoclonal anti-WASp F-8 Ab (Santa Cruz Biotechnology) were added to the rest of pre-cleared supernatant and immunoprecipitation was performed during $10 \mathrm{~h}$ at $4{ }^{\circ} \mathrm{C}$ on shaking platform. Resulted ChIP samples were added to $100 \mu \mathrm{L}$ per sample of pre-equilibrated protein GSepharose beads suspension with further incubation during $4 \mathrm{~h}$ at $4{ }^{\circ} \mathrm{C}$ on shaking platform. Triple wash of IP samples was performed via beads re-suspension in $1 \mathrm{~mL}$ of cold 1x PBS followed by centrifugation (1000 rpm, 
a
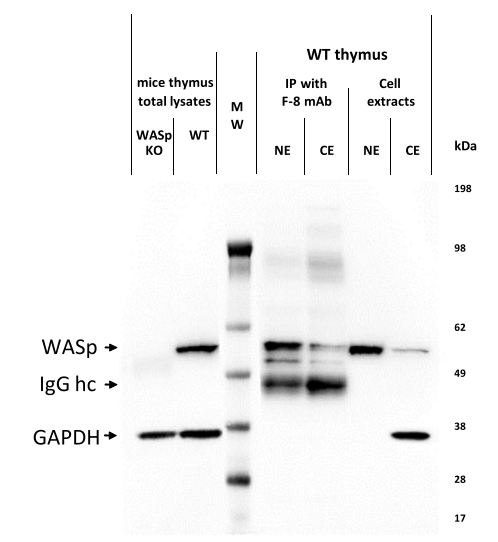

C
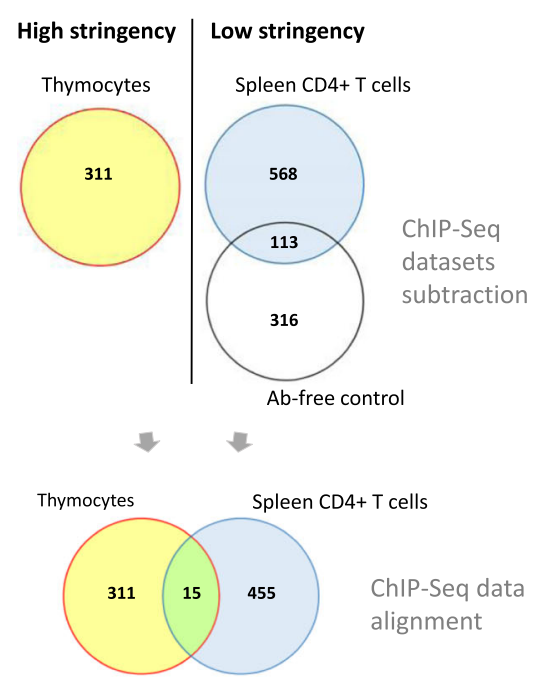

b

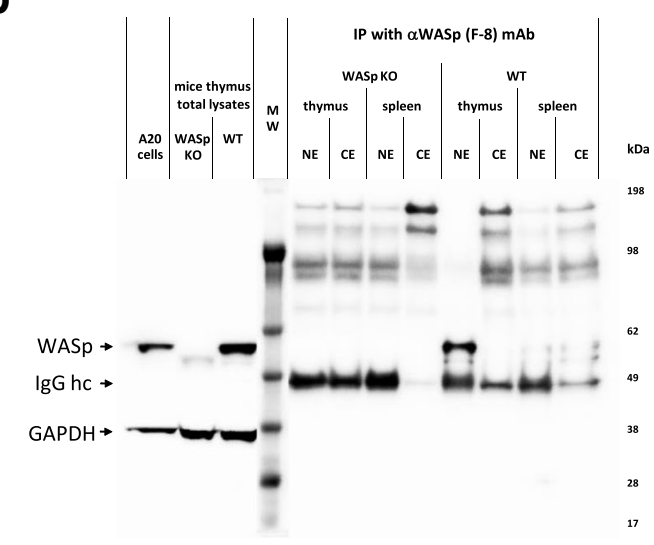

d

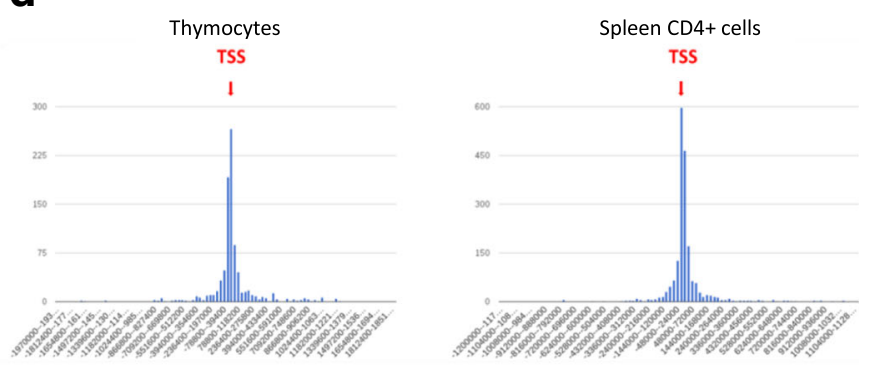

e

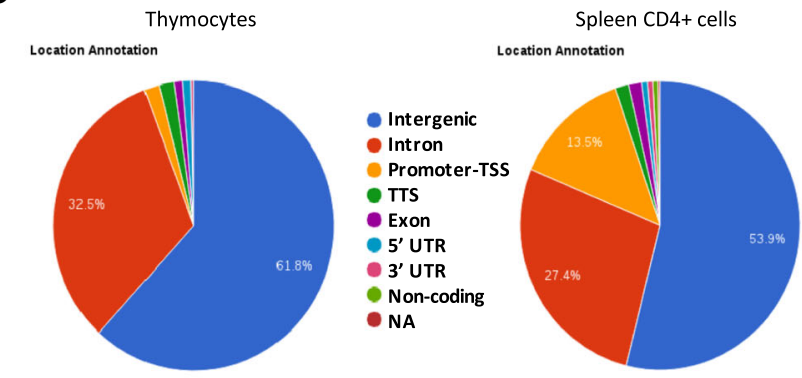

f
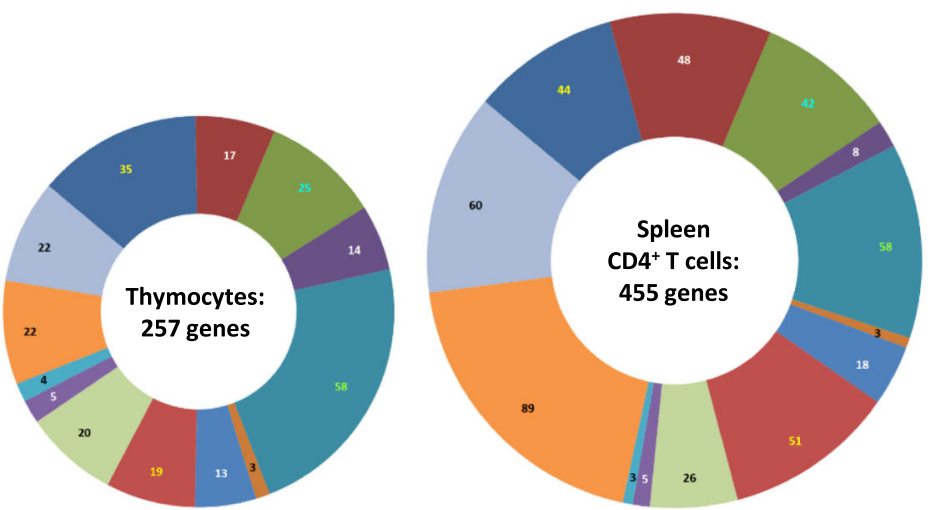

- Transcription factors \& co-factors

- Other DNA or RNA binding factors

= Cytoskeleton network \& motors

- Cell-cell interaction and adhesion

n Signaling enzymes, receptors \& associated proteins

arell cycle

a Proteolysis

- Metabolic \& energy enzymes

= Channels \& transporters

Extracellular matrix

n Gametogenesis

= Conserved genes with non-determined function

= RIKEN \& predicted genes

Fig. 1 (See legend on next page.) 


\begin{abstract}
(See figure on previous page.)
Fig. 1 ChIP-seq analysis of WASp enriched genes. a The F-8 anti-WASp Ab specifically recognizes WASp in total thymocyte lysates, nuclear extracts (NE), and cytosolic extracts (CE). Heavy chain of mouse lgG (IgGhc) is observed in eluted IP samples. GAPDH was used as a sample loading control for total lysates. $\mathbf{b}$ WASp is abundant in NE of WT thymocyte when compared to NE of WT spleen CD4 ${ }^{+} \mathrm{T}$ cells. Heavy chain of mouse $\lg \mathrm{G}(\mathrm{lg} \mathrm{Ghc}$ ) is observed in eluted IP samples. GAPDH was used as a sample loading control for total lysates. These data are representative of four (thymus fractionation) and two (spleen $\mathrm{CD}^{+} \mathrm{T}$ cell fractionation) independent biological replicates. c ChIP-seq analysis of thymocytes and spleen $\mathrm{CD}^{+} \mathrm{T}$ cells flowchart. WASp-enriched genes by ChIP-seq analysis of WT thymocytes performed under high stringency condition. WASp-enriched genes by ChIP-seq analysis of spleen CD4 ${ }^{+} T$ cells performed under low stringency conditions and compared to a ChIP-seq dataset from control Ab-free spleen CD4 ${ }^{+} \mathrm{T}$ cells. All common genes were subtracted from the spleen $\mathrm{CD}^{+} \mathrm{T}$ cells dataset. Both ChIP-seq datasets were then aligned and compared to identify common genes in thymocytes and spleen CD4 ${ }^{+} \mathrm{T}$ cells. $\mathbf{d}$ Distribution of distance from WASp ChIP-seq gene peaks to the nearest transcription start site (TSS) defined according to the positions of RefSeq TSSs using the CHIPseek software. Negative values indicate $5^{\prime}$ of the TSS, positive values indicate 3' of the TSS. e Annotation of WASp ChIP-seq gene peak positions within intergenic and genic regions using CHIPseek software. By default promoter-TSS annotation defined as area from $-1 \mathrm{~kb}$ to $+100 \mathrm{bp}$ of the TSS position and transcription termination site area (TTS) defined from - $100 \mathrm{bp}$ to $+1 \mathrm{~kb}$ of the TTS position. f Functional groups of peak-corresponding genes in WASp ChIP-seq refined datasets. Additional file 1: Figure S1-S3 and Additional file 3: sheets 1 and 2
\end{abstract}

$3 \min , 4{ }^{\circ} \mathrm{C}$ ) and collection of supernatant. For high stringency, the beads were washed twice with RIPA buffer, pH 7.6 (50 mM HEPES-KOH pH 7.6, $100 \mathrm{mM} \mathrm{NaCl}$, $1 \mathrm{mM}$ EDTA, $500 \mathrm{mM} \mathrm{LiCl}, 1 \% \mathrm{NP}-40,0.7 \%$ sodium deoxycholate). For low stringency, the beads were washed twice with cold 1x PBS or TE buffer containing $50 \mathrm{mM} \mathrm{NaCl}$. Finally, beads were re-suspended in elution buffer, $\mathrm{pH} 8.0$ (1\% SDS, $50 \mathrm{mM}$ tris- $\mathrm{HCl}, 10 \mathrm{mM}$ EDTA) and incubated for $2 \mathrm{~h}$ at $65{ }^{\circ} \mathrm{C}$ followed by incubation for $10 \mathrm{~h}$ at $56{ }^{\circ} \mathrm{C}$ with $100 \mu \mathrm{L} / \mathrm{mL}$ proteinase $\mathrm{K}$, \#19133 (QIAGEN). Quality control of ChIP DNA fragments was performed using Bioanalyzer 2100 with High Sensitivity DNA Kit, \#5067-4626 (Agilent) to ensure that the size of DNA fragments was in the range of 100800 bp (Additional file 1: Figure S2A). Library construction for ChIP-seq and DNA sequencing (10 M clean data) using the Illumina Genome Analyzer platform was performed at Beijing Genome Institute (BGI, Shenzhen). ChIP validation polymerase chain reaction (PCR) was performed on a number of identified gene targets to confirm specific DNA enrichment vs. ChIP Ab-free negative control sample.

\section{Western blotting}

Western blotting was performed using the Bolt electrophoresis system (Invitrogen) and Bolt ${ }^{\text {tw }} 4-12 \%$ Bis-Tris Plus polyacrylamide gels NW04120BOX (Thermo Fisher Scientific) in 1x Bolt ${ }^{\circ}$ MOPS SDS Running buffer B0001 (Thermo Fisher Scientific). Blots were processed in $1 \mathrm{x}$ TBS-T buffer containing 5\% non-fat dry milk \#1706404 (Bio-Rad) with antibodies used as follows: WASp F-8 (Santa Cruz Biotechnology), TCF1 H-118 (Santa Cruz Biotechnology) diluted 1:200, TCF12 PA5-21039 (Invitrogen) diluted 1:300, GAPDH (FL-355, Santa Cruz Biotechnology) diluted 1:1000, histone H3 (ab1791, Abcam) diluted 1:10,000. Detection of GAPDH was used as a sample loading control for total lysate and for cytosolic extract. Detection of histone H3 was used as a sample loading control for nuclear extract. Blots were developed using IgG-HRP labeled antibodies (Santa Cruz Biotechnology) and the ECL detection system. Blot images were analyzed using the ImageQuant LAS 4000 LAS4000 Image system using ImageQuant LAS 4000 Control Software (GE Healthcare). The images of pre-stained Protein Standard SeeBlue Plus2 LC5925 (Thermo Fisher Scientific) and sample loading controls derived from the same gel run, were overlaid onto blot image using Adobe Photoshop CS6. The quantification of protein band intensity on western blots was performed using ImageJ software and normalized integrated signal density was determined with Excel software.

\section{Fluorine-conjugated UTP (FUrd) incorporation transcription assay}

For the in vivo run-on assays to monitor nascent precursor RNA polymerase II transcripts [41], the thymocyte cell suspension was incubated with $0.04 \mu \mathrm{g} / \mathrm{mL}$ of actinomycin D in RPMI media for $2 \mathrm{~h}$, then cells were treated with $2 \mathrm{mM}$ FUrd (Sigma-Aldrich) for $15 \mathrm{~min}$. To stop the reaction, cells were washed twice with cold $1 \mathrm{x}$ PBS; then the cell suspension was applied on glass slides. Cells were fixed using 3.7\% formaldehyde in 1x PBS, permeabilized with $0.5 \%$ Triton $-\mathrm{X} 100$ in $1 \mathrm{x}$ PBS, then incubated with anti-BrdU Ab (Life Technology) to detect FUrd incorporation into nascent RNA. In addition, antihistone $\mathrm{H} 3$ ab1791 (Abcam) was applied for the detection of nuclei pattern. For the microscopy analysis, cells were mounted in Prolong Gold mounting medium containing DAPI (Molecular Probes) and a single image representing the focal plane was captured using Leica DMRXA microscope at $\times 200$ and $\times 1000$ magnifications. Several randomly distributed cells were captured for each sample. Images were processed using Openlab 3.1.4 software (Improvision) and Adobe Photoshop 8.0. For quantification, the cells as defined by DAPI signal were outlined and the integrated density of FUrd fluorescence signal was calculated using ImageJ software. Ten cells with the brightest FUrd signal found on each image were 
taken for subsequent analysis. The obtained integrated density of the signal was normalized for the main value found in the WT cells. Statistical analysis was performed in GraphPad Prism and Excel software. Chosen sample size covered all available detected signals in the limited dataset of WASp KO mice in the first experimental round. A similar sample size was chosen in available WASp $^{\text {I296T }}$ mice in the second experimental round. To create a balanced design, the same sample size was chosen in WT mice in both rounds of experiments. Statistical analysis of nested ANOVA was applied in both rounds of experiments. Analysis in the first experimental round-FUrd signal measurements in WASp KO vs. WT mice-was performed with the following parameters: exact values of $\mathrm{N}$ : 90 for each mice (nine images with ten measured values); 180 for each genotype; definition of the center in WT1-3: 9603; 8069; 7686; definition of the center in WASp KO1-3: 3613; 3832; 5150; mean \pm SD in WT1-3: 11,420 $\pm 7007 ; \quad 9644 \pm 5532$; $10,019 \pm 6145$; mean \pm SD in WASp KO1-3: 6374 \pm 5540 ; $5448 \pm 3959 ; 7046 \pm 4882$. Analysis in the second experimental round-FUrd signal measurements in WASp ${ }^{\text {I296T }}$ vs. WT mice-was performed with following parameters: exact values of N: 60 for each mice (six images with ten measured values); 240 for each genotype; definition of the center in WT1-4: 782,452; 507,618; 703,523;

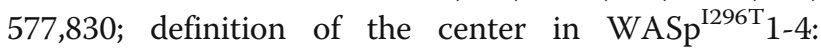
660,$231 ; 503,051 ; 517,926 ; 587,749$; mean \pm SD in WT1$4: \quad 857,222 \pm 434,228 ; \quad 686,248 \pm 518,108 ; \quad 781,260 \pm$

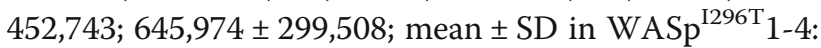
$753,605 \pm 401,440 ; 564,983 \pm 247,523 ; 701,733 \pm 537,852$; $612,138 \pm 279,542$. Exact $p$ values in FUrd incorporation transcription assay in the first experimental round (WASp KO vs. WT): $p=0.0046$; in the second experimental round (WASp ${ }^{\mathrm{I} 296 \mathrm{~T}}$ vs. WT): $p=0.2337$.

\section{Real-time quantitative PCR-based gene expression profiling}

Gene specific primers designed with Primer Bank software are listed in Additional file 2. Total RNA from thymocytes was isolated with RNeasy kit \#74104 (QIAGEN). Genomic DNA nuclease treatment with RNAse-free DNAse kit \# 79254 (QIAGEN) was performed during isolation procedure for each prepared total RNA sample. The concentration of isolated total RNA was measured by NanoDrop 2000 (Thermo Scientific). The visual quality control for RNA integrity and purity was performed by $1 \%$ UltraPureAgarose, \#16500500 (Invitrogen), 1x TAE gel electrophoresis analysis. Gel images were created with ImageQuant LAS 4000 LAS4000 Image system using ImageQuant LAS 4000 Control Software (GE Healthcare). Two micrograms of total RNA per sample was used for each complementary DNA (cDNA) synthesis reaction (with
SuperScript ${ }^{\text {tax }}$ II Reverse Transcriptase, \#18064-014 (Invitrogen). Real-time quantitative PCR (RT-qPCR) reactions were performed using SsoAdvanced ${ }^{\mathrm{T}}$ Universal SYBR $^{\circ}$ Green Supermix kit, \#1725272SP (Bio-Rad) with C1000/CFX96 RT-PCR System (Bio-Rad). Gene expression profiling by RT-qPCR was performed in three technical replicates for each cDNA template sample with $\mathrm{Ct}$ variation between triplicates less than cut-off \pm 0.25 . Gene expression data: the mean of the technical triplicate, $\Delta \mathrm{Ct}$, RQ value, and standard deviation between RQ of biological triplicates were calculated and analyzed using Excel software.

\section{Bioinformatics analysis}

Standard bioinformatics analysis of ChIP-seq data was performed by BGI (Shenzhen, Guangdong, China) including primary data filtering to remove adaptor sequences, contamination and low-quality reads from raw reads, read alignment, and genome-wide distribution of ChIP-seq reads (Table 1), general classification of all hits, GO function analysis of peak-related genes, sequence analysis using Motif discovery tool (MEME) and Motif Alignment and Search Tool (MAST). Peaks were identified using peak calling approaches MACS (Model-based Analysis for ChIP-Seq) and SICER (spatial clustering approach for the identification of ChIP-enriched regions) [42-44]. Differential binding peaks were obtained by software MAnorm as described [45]. Functional classification of refined data for peak-related genes was performed using NCBI Gene resource (Bethesda, MD, USA). All hit classification diagrams were made with Excel software. Distribution of distances from gene peak reads to the nearest transcription start site (TSS) were defined according to the positions of RefSeq TSSs using ChIPseek software [46]. Genomic annotation of gene peak positions within intergenic and genic regions was received using ChIPseek software. By default, promoter-TSS annotation is defined as the area from $-1 \mathrm{~kb}$ to $+100 \mathrm{bp}$ of the TSS position and the transcription termination site area (TTS) is defined from $-100 \mathrm{bp}$ to $+1 \mathrm{~kb}$ of the TTS position [46]. DNAbinding site inference for DNA-interacting protein partner of WASp was assessed by applying TRANSFAC ${ }^{\circ}$ software [47]. Distribution of activating and repressive epigenetic marks and specific TF sites in selected candidate genes resulted from ChIP-seq data was examined using the UCSC Genome Browser tool suite. Intra-intronic positions of certain peak reads and distances from peak reads to nearest exon of genes selected from ChIP-seq data were identified with UCSC Genome Browser tool suite.

\section{Results}

WASp localizes to the nucleus in thymocytes

To examine the presence of WASp in the nucleus during development of $\mathrm{T}$ cells, nuclear and cytosolic 
Table 1 ChIP sample statistics

\begin{tabular}{|c|c|c|c|c|c|c|c|c|}
\hline Source & Cell type & Sample name & $\begin{array}{l}\text { Read } \\
\text { length }\end{array}$ & $\begin{array}{l}\text { Clean } \\
\text { reads }\end{array}$ & $\begin{array}{l}\text { Mapped } \\
\text { reads }\end{array}$ & $\begin{array}{l}\text { Mapped } \\
\text { rate (\%) }\end{array}$ & $\begin{array}{l}\text { Unique mapped } \\
\text { reads }\end{array}$ & $\begin{array}{l}\text { Unique mapped } \\
\text { rate (\%) }\end{array}$ \\
\hline WT thymus sample 1 & Thymocytes & Sample2 & 49 & 10955383 & 10625818 & 96.99 & 8955583 & 81.75 \\
\hline $\begin{array}{l}\text { WT spleen CD4+ T cells } \\
\text { sample }\end{array}$ & $\begin{array}{l}\text { Spleen CD4+ } \\
\text { T cells }\end{array}$ & Sample4 & 49 & 31269031 & 30709811 & 98.21 & 27032898 & 86.45 \\
\hline $\begin{array}{l}\text { Ab-free WT spleen negative } \\
\text { control } 1\end{array}$ & $\begin{array}{l}\text { Spleen CD4+ } \\
\text { T cells }\end{array}$ & Sample5 & 49 & 31288824 & 30704013 & 98.13 & 27032749 & 86.4 \\
\hline WT thymus sample 2 & Thymocytes & Sample12 & 49 & 9864439 & 9538121 & 96.69 & 8449710 & 85.66 \\
\hline WASp thymus I296T sample & Thymocytes & Sample13 & 49 & 15526660 & 15110656 & 97.32 & 13339372 & 85.91 \\
\hline WT thymus input control & Thymocytes & Sample2_input & 49 & 12495831 & 12274173 & 98.23 & 10449083 & 83.62 \\
\hline $\begin{array}{l}\text { WT spleen CD4+ T cells } \\
\text { input control }\end{array}$ & $\begin{array}{l}\text { Spleen CD4+ } \\
\text { T cells }\end{array}$ & Sample4_input & 49 & 12658673 & 12522710 & 98.93 & 10976914 & 86.71 \\
\hline
\end{tabular}

extracts were prepared from thymus single-cell suspension consisting of $>98 \%$ thymocytes and from spleen $\mathrm{CD} 4^{+} \mathrm{T}$ cells. We reasoned that WASp may not be an easy protein to ChIP for based on its high homology to N-WASp and the fact that WASp may be associated with actin. To avoid cross-reactivity with N-WASp, we tested a panel of anti-WASp antibodies and screened them on cell lysates from WT and WASp KO thymocytes. We identified that the WASp F-8 Ab specifically detected WASp in total lysates from WT thymocytes while no band was detected in WASp KO thymocytes (Fig. 1a). To examine if WASp was present in the nucleus of thymocytes, nuclear and cytosolic extracts were prepared and WASp was detected both in nuclear and cytosolic extracts and could be immunoprecipitated from the nuclear and cytosolic extracts (Fig. 1a). When comparing immunoprecipitated WASp from nuclear and cytosolic extracts from thymus and spleen $\mathrm{CD} 4^{+} \mathrm{T}$ cells, WASp was almost exclusively detected in the thymus nuclear extract; much less WASp was detected in the nuclear extract of spleen $\mathrm{CD} 4^{+} \mathrm{T}$ cells (Fig. 1b). These data show that the WASp F-8 Ab immunoprecipitates WASp from nuclear and cytosolic extracts of thymocytes and to a lesser extent from spleen $\mathrm{CD} 4^{+} \mathrm{T}$ cells.

\section{WASp interacts with DNA in both intergenic and genic regions}

To investigate the potential association of WASp with the mammalian genome, we prepared thymocyte and spleen $\mathrm{CD}^{+} \mathrm{T}$ cells lysates and performed ChIP-seq analysis using the WASp F-8 Ab. Since thymocyte nuclear extracts contained abundant WASp, ChIP-seq was performed under high stringency for cross-linking/washing (1\% formaldehyde [FA]/RIPA wash, Additional file 1: Figure S2A, B). The total number of reads were normalized and aligned against the mouse genome to identify regions enriched for WASp binding (Additional file 1: Figure S2E). We identified 311 WASp enriched genes in the WASp ChIP dataset from WT thymocytes (Fig. 1c).
For spleen $\mathrm{CD}^{+} \mathrm{T}$ cells with less WASp in the nucleus, ChIP-seq was performed under low stringency for crosslinking/washing $(10 \mathrm{mM}$ dimethyladipimidate $[\mathrm{DMA}] \pm$ $0.75 \%$ FA/PBS wash, Additional file 1: Figure S2C). To circumvent this difference in ChIP sample preparation between thymus and spleen $\mathrm{CD}^{+} \mathrm{T}$ cells, we included an Ab-free control for spleen $\mathrm{CD}^{+} \mathrm{T}$ cells performed under low stringency (Additional file 1: Figure S1C). For analysis of spleen $\mathrm{CD}^{+} \mathrm{T}$ cells, all genes present in the Ab-free dataset were subtracted from the WASp ChIP sample (Fig. 1c). Since 54 of the genes from the Ab-free dataset were found in the thymocyte WASp ChIP-seq dataset, we excluded these 54 genes from the thymocyte dataset (Fig. 1c). Upon extraction of the sequences in the Ab-free control, the ChIP-seq datasets from thymocytes contained 257 WASp-interacting genes (Fig. 1c and Additional file 3: sheet 1) and 455 WASpinteracting genes from spleen $\mathrm{CD}^{+} \mathrm{T}$ cells (Fig. 1c and Additional file 3: sheet 2). When the ChIP-seq datasets from thymocytes and spleen $\mathrm{CD}^{+}{ }^{+} \mathrm{T}$ cells were compared, 15 common WASp-interacting genes were identified (Fig. 1c). To confirm efficiency of performed ChIP procedure, selected genes were validated by RT-qPCR using the ChIP samples from thymocytes (Additional file 1: Figure S2G, H). Moreover, we sequenced the thymocyte and spleen $\mathrm{CD}^{+} \mathrm{T}$ cell input ChIP samples and found more than tenfold enrichment of WASp ChIP-seq enriched genes (Additional file 1: Figure S3). In thymocytes and in spleen $\mathrm{CD}^{+} \mathrm{T}$ cells, WASp was clustered around the TSSs (Fig. 1d) and WASp interacted with both intergenic and genic regions of which the majority were intron sequences (Fig. 1e). Functional clustering of these genes using the NCBI Gene resource revealed that WASp was associated with RNA Polymerase II genes involved in a wide range of biological function that were divided into 13 functional groups (Fig. 1f). Among identified genes are TFs and co-factors (Nfatc2, TCF12, Mllt1, Rprd1b, Rprd2, Taf1b, Zfp438), other DNA and RNA-interacting proteins (Rad51d, Exosc10, Rbm20), 
regulators of signal transduction (Arhgap26, Phlpp1, Vav2, Vav3), cytoskeleton-associated proteins (Alms1, Cenpe, Nebl, Palld, WAVE2), and molecular motors (Myh9, Myh10; see Additional file 3: sheets 1 and 2).

\section{Genome-wide DNA occupancy of WASp associated with RNA Polymerase II genes}

We used the tools available at the University of California Santa Cruz (UCSC) genome browser to characterize the association of the WASp ChIP-seq-binding profile with RNA Polymerase II promoters and epigenetic marks for active and repressed transcription as well as association with peaks obtained by ChIP for specific TFs and by DamID of genome-nuclear lamina interactions for nuclear envelope lamin B1 [48] (Fig. 2a). Many of the WASp-enriched genes were associated with RNA Polymerase II-enriched genes (Fig. 2a). WASp-enriched sequences of $T c f 12$ were associated with RNA Polymerase II binding and active epigenetic marks of transcription; H3K4m3, H3K9a, H3K27a, and with the epigenetic mark for active enhancers H3K4m1 (Fig. 2a and b). WASpenriched sequences of Vav2 and WASf2 were associated with RNA Polymerase II binding and active epigenetic marks of transcription H3K27a and/or active enhancers H3K4m1 (Fig. 2a and b). WASp-enriched sequences were found close to the TSS of Nfatc2, Trim50, Nebl, WASf2, Palld, Tcf12, Cct4, Sec24a, Rbm20, Zfp438, Zpbp (Fig. 3a, Additional file 1: Figure S4A) and in deep intronic regions for Vav2, Taf1b, and other genes (Fig. 3b, Additional file 1: Figure S4B). These data suggest that WASp associates at the promoter with RNA Polymerase II and epigenetic marks for active transcription.

\section{Global and gene-specific transcription is repressed in WASp KO thymocytes}

To examine the role of WASp in global gene transcription, we performed a run-on transcription assay on living cells in which fluorine-conjugated UTP (FUrd) analogues are incorporated into nascent messenger RNA (mRNA) molecules [41, 49]. Since WASp KO thymocytes have reduced capacity to respond to T cell receptor stimulation [21, 28-30], we examined mRNA transcription in naïve thymocytes. When compared to WT thymocytes, WASp KO thymocytes showed less intense FUrd-rich foci, suggesting that WASp is required for basal transcription (Fig. 4a, b). We next compared general synthesis of nascent mRNA molecules in WT thymocytes with thymocytes expressing the constitutively active mutation of WASp, WASp ${ }^{\text {I296T }}$, and found similar intensity of FUrd-rich foci in WT and WASp ${ }^{\text {I296T }}$ thymocytes (Fig. 4a, b).

To understand how WASp influences gene transcription of specific genes, we next isolated total mRNA from WT and WASp KO thymocytes and compared gene expression using RT-qPCR. From the WASp ChIP-seq dataset of WASp-interacting genes, we selected 76 genes encoding for proteins associated with cytoskeletal networks and 76 genes encoding for proteins in transcriptional networks and performed expression profiling (Additional file 1: Figure S5). Many of these genes were differentially expressed in WT and WASp KO thymocytes (Fig. 4c), suggesting that WASp regulates gene transcription at several loci.

We next compared expression of selected genes including the 15 common WASp-interacting genes in the ChIP-seq datasets for thymocytes and spleen $\mathrm{CD} 4^{+} \mathrm{T}$ cells. Of these genes, 11 out of 17 genes showed lower expression in WASp KO thymocytes when compared to WT thymocytes, including Mir6369, Trim50, Vav2, Phlpp1, Vav3, Prkca, Slc30a4, Plcb4, Prkcb, Zpbp, and Tcf12 (Fig. 4d). Six out of 17 genes showed higher expression in WASp KO thymocytes when compared to WT thymocytes, including Sec24a, Nebl, Nfatc2, Plcb1, GM13152, and WASf2 (Fig. 4d). Together these data suggest that WASp is involved in both transcription activation and repression of specific genes.

\section{Gene regulation by nuclear WASp ${ }^{1296 T}$}

To examine the genomic distribution of the constitutively active form of WASp [37], WASp ${ }^{\text {I296T }}$, we performed ChIP-seq analysis using the WASp F-8 Ab under low stringency conditions (10 mM DMA/PBS wash, Additional file 1: Figure S2D). To pre-process raw ChIPseq data, the total number of reads were normalized and aligned against the mouse genome to identify regions enriched in WASp ${ }^{\mathrm{I} 296 \mathrm{~T}}$ binding (Additional file 1: Figure S2F). We obtained differential binding peaks between thymocytes expressing WT WASp or WASp ${ }^{\text {I296T }}$ and identified $70 \mathrm{WASp}^{\mathrm{I}}{ }^{\mathrm{I} 96 \mathrm{~T}}$-enriched genes (Fig. 5a and Additional file 3: sheet 3). Functional clustering of these genes revealed that WASp ${ }^{\text {I296T }}$ was associated with RNA Polymerase II genes in 11 functional groups (Fig. 5a). Among the identified genes were regulators of signal transduction (Lck, ZAP70), cytoskeleton-associated proteins (Coro2a), and molecular motors (Myo1b, Supplementary file 1 sheet 3). From the ChIP-seq dataset of WASp ${ }^{1296 \mathrm{~T}}$-interacting genes, we selected 16 genes and performed expression profiling (Fig. 5b). Of these genes, six of the 16 genes showed lower expression in WAS$\mathrm{p}^{\mathrm{I} 296 \mathrm{~T}}$ thymocytes when compared to WT thymocytes, including Gas7, Thrb, Ap3m2, Tmem189, Ccdc88a, and ZAP70 (Fig. 5b). Ten of the 16 genes showed higher expression in WASp ${ }^{\text {I296T }}$ thymocytes when compared to WT thymocytes, including Myo1b, Lck, Itgb3, Zcchc4, Coro2a, Zc3h11a, SH3kbp1, Med12I, and Scaf8 (Fig. 5b). Together these data suggest that thymocytes expressing constitutively active WASp ${ }^{\text {I296T }}$ had same intensity of 
a

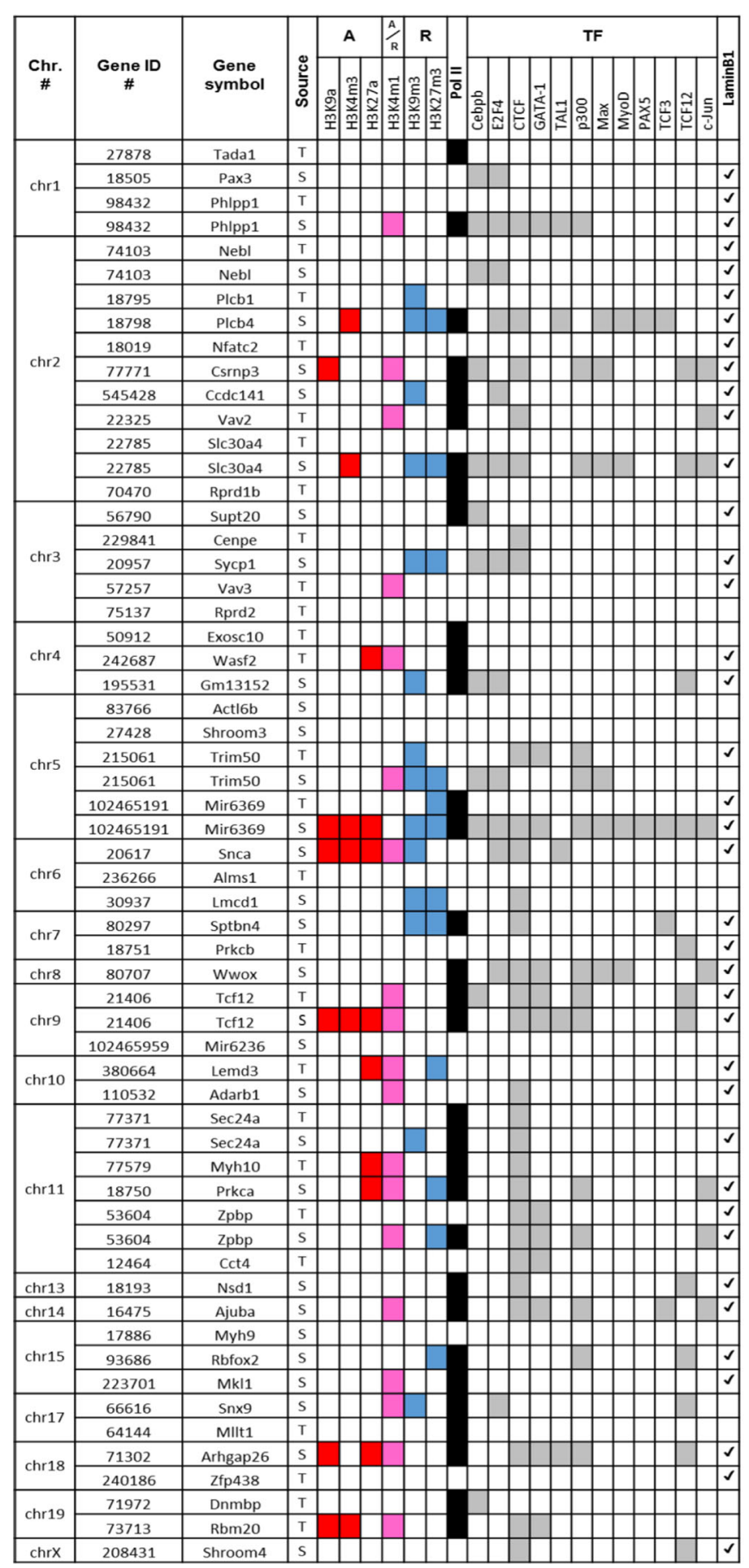

\section{b}
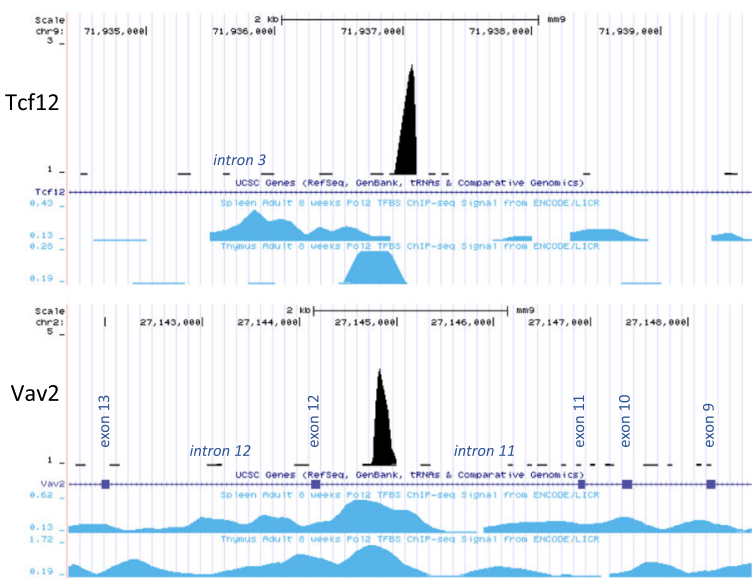

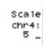

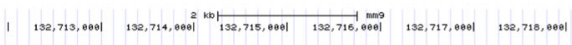

Wasf2

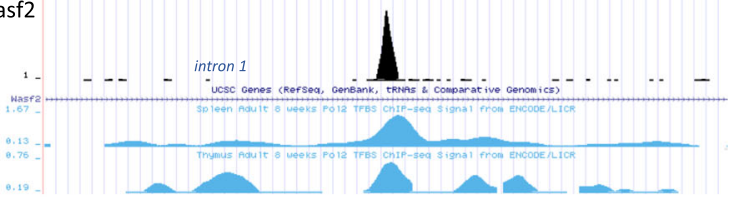

Fig. 2 Transcription matrix for selected WASp enriched genes. a Bioinformatic association of WASp ChIP-seq peaks from our datasets with activating (A) and/or repressive (R) epigenetic regulatory marks, RNA Polymerase II and TFs peaks and lamin B1 marks in thymocytes (T) and spleen CD4 ${ }^{+}$cells (S). b Association of WASp ChIP-seq peaks in thymocytes of Tcf12, Vav2, and Wasf2 with RNA Polymerase II ChIP-Seq signal by TFBS ENCODE/LICR resource at UCSC genome browser 
a

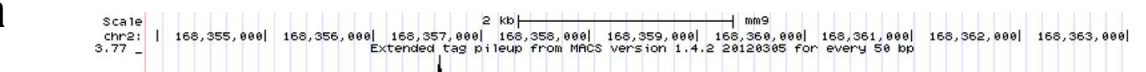
Nfatc2 (1)

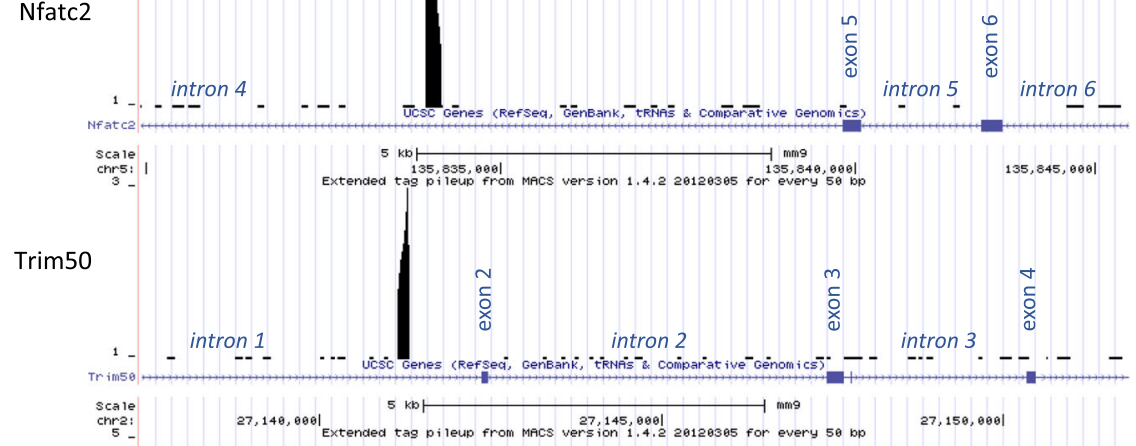

Vav2

chre:

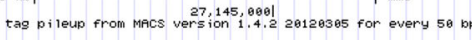

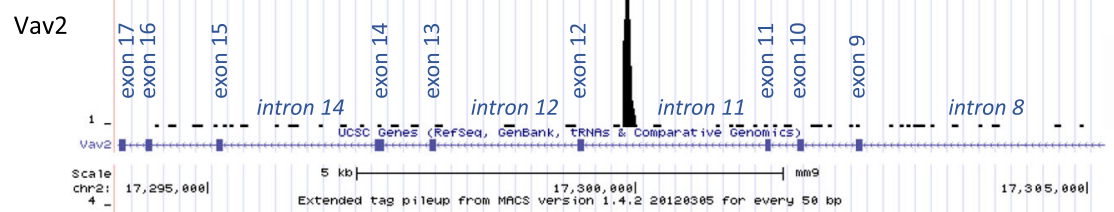

Nebl

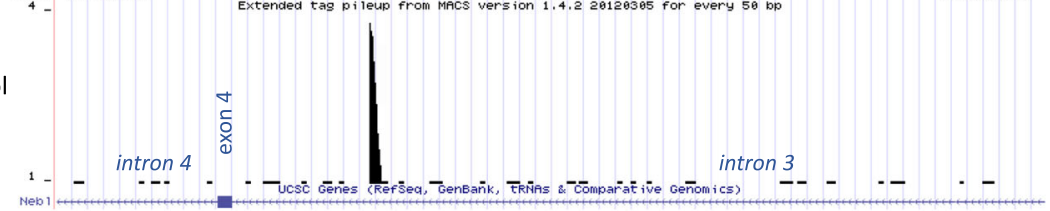

b

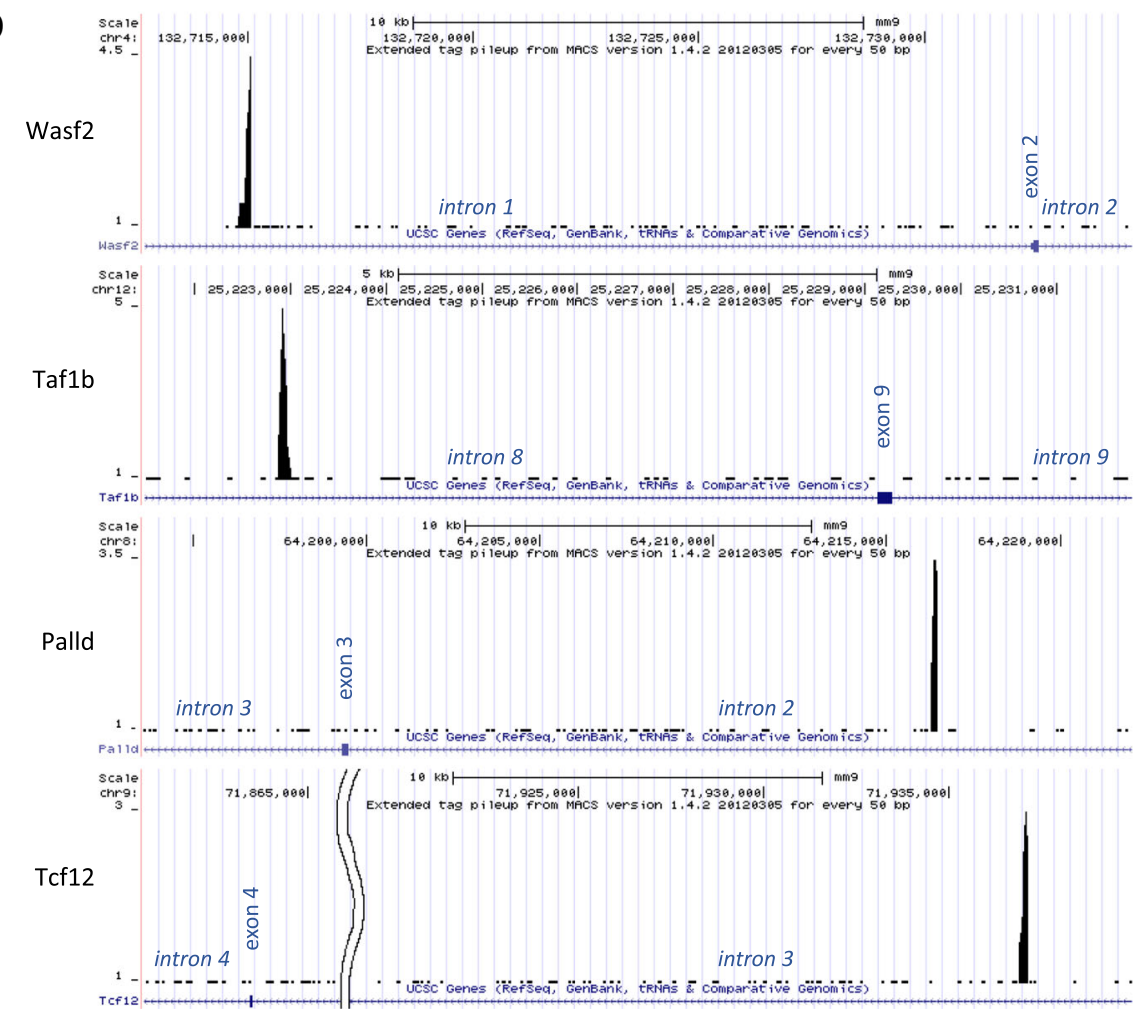

Fig. 3 Variation of distances from WASp ChIP-Seq gene peaks to nearest exon(s). Selected examples of genes with (a) shorter distance range $(0.5-5 \mathrm{~kb})$ and $(\mathbf{b})$ longer distance range (5-50 kb) between WASp ChIP-seq gene peak position and nearest exon. Additional file 1: Figure S4 


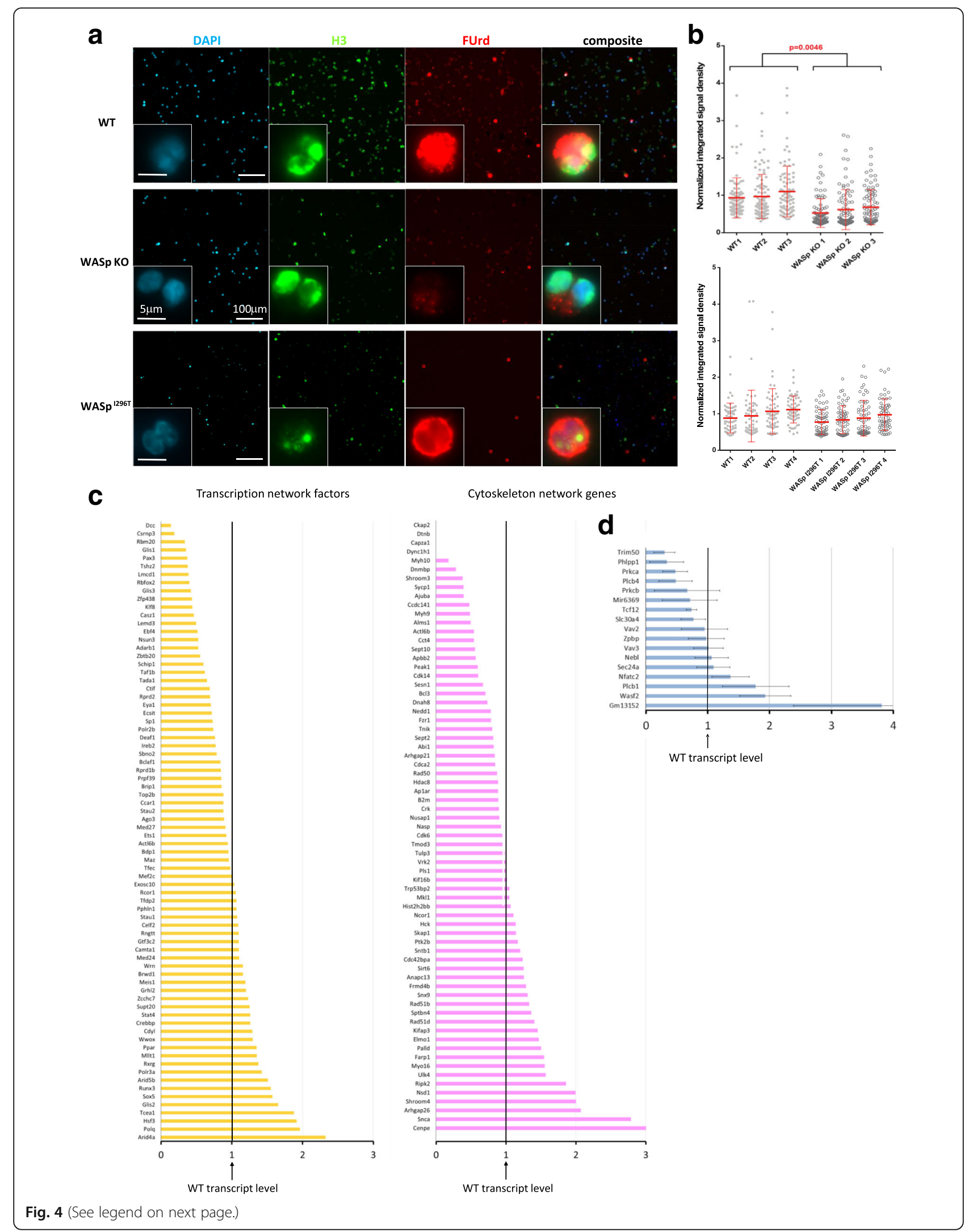


(See figure on previous page.)

Fig. 4 WASp functional status affects both basal and gene-specific transcription. a FUrd incorporation assays data for basal RNA polymerase II nascent transcripts in WT, WASp KO, and WASp ${ }^{1296 T}$ thymocytes as determined by intensity of FUrd-rich foci (red). The cell nucleus is labeled with DAPI (blue) and histone H3 (green). Note that mRNA transcripts can be seen in the cytoplasm already after 15 min. b Statistical analysis of FUrd assay results by nested ANOVA. Each dot represents one image. Top: WT $n=3$, WASp KO $n=3$ in one experiment; bottom: WT $n=4, X L N^{1296 T}$ $\mathrm{n}=4$ in one experiment. $\mathbf{c}$, $\mathbf{d}$ Gene expression profiling by RT-qPCR of WASp ChIP-seq genes (c) encoding TFs, other DNA- or RNA-binding proteins, and cytoskeletal network proteins performed on CDNA template of pooled samples: WASp KO $n=3$ vs. WT $n=3$ and (d) for common WASp-enriched genes in thymocytes and spleen CD4 ${ }^{+} \mathrm{T}$ cells. Expression in WASp KO thymocytes is shown and compared with expression level in WT thymocytes set to 1. Gene expression profiling by RT-qPCR was performed in three biological replicates: WASp KO $n=3$ vs. WT $n=3$ and in three technical replicates for each CDNA template sample with Ct variation between triplicates less than cutoff \pm 0.25 . Gene expression data: the mean of the technical triplicate, $\Delta C t, R Q$ value, and standard deviation between RQ of biological triplicates is indicated. See Additional file 1: Figure S5

basal gene transcription (Fig. 4a, b) and induced higher expression of specific genes (Fig. 5b).

\section{Association between WASp, TCF12, and TCF1 in the nucleus}

Tcf12 was one of the 15 WASp-enriched genes present in both thymocytes and spleen $\mathrm{CD} 4^{+} \mathrm{T}$ cells. To understand how the activity of WASp influences expression of the Tcf12 gene, TCF12 was examined in T cells from WT, WASp KO, WASp ${ }^{\text {L272P }}$, and WASp ${ }^{\text {I296T }}$ mice, the latter two expressing a constitutively active form of WASp [37]. Since TCF12 is mainly localized in the nucleus, we examined TCF12 in nuclear and cytosolic extracts from WT, WASp KO, WASp ${ }^{\mathrm{L} 272 \mathrm{P}}$, and WASp ${ }^{\text {I296T }}$ thymocytes. TCF12 was predominantly expressed in the nuclear extract of WT thymocytes (Fig. 6a). WASp KO thymocytes had significantly reduced TCF12 signal that was barely detected in the cytosolic extracts (Fig. 6a).
This was in contrast to thymocytes expressing the constitutively active form of WASp. Both WASp ${ }^{\text {L272P }}$ and WASp $^{\text {I296T }}$ thymocytes had increased TCF12 in the nuclear extract and in the cytosolic extract when compared to WT thymocytes (Fig. 6a). These data suggest that the activation status of WASp influences the level of nuclear TCF12 protein in thymocytes.

To understand how WASp regulated Tcf12 expression, we examined if WASp contained any described DNAbinding structural motifs or documented DNAinteracting properties and found no such evidence using gene ontology tools provided by MGI at NCBI Gene resource (Additional file 4). This suggests that the association of WASp with DNA may be indirect and mediated by interaction with DNA-binding proteins. We analyzed if there was any conserved DNA-binding site(s) in the WASp-enriched sequences from the ChIP-seq datasets from WT thymocytes and from WASp ${ }^{\mathrm{I} 296 \mathrm{~T}}$ thymocytes. a

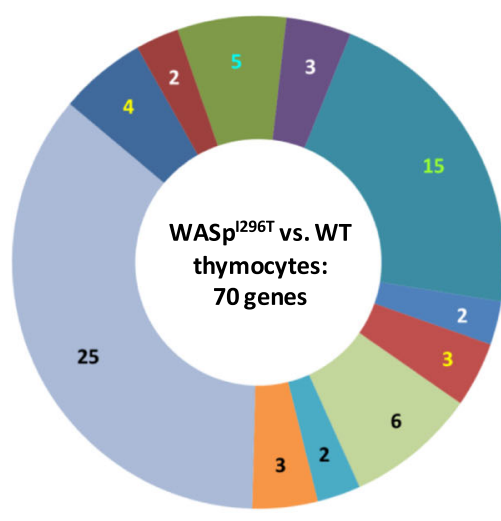

- Transcription factors \& co-factors

= Other DNA or RNA binding factors

n Cytoskeleton network \& motors

a Cell-cell interaction and adhesion

n Signaling enzymes, receptors \& associated proteins

a Proteolysis

netabolic \& energy enzymes

$=$ Channels \& transporters

a Gametogenesis

= Conserved genes with non-determined function

= RIKEN \& predicted genes b

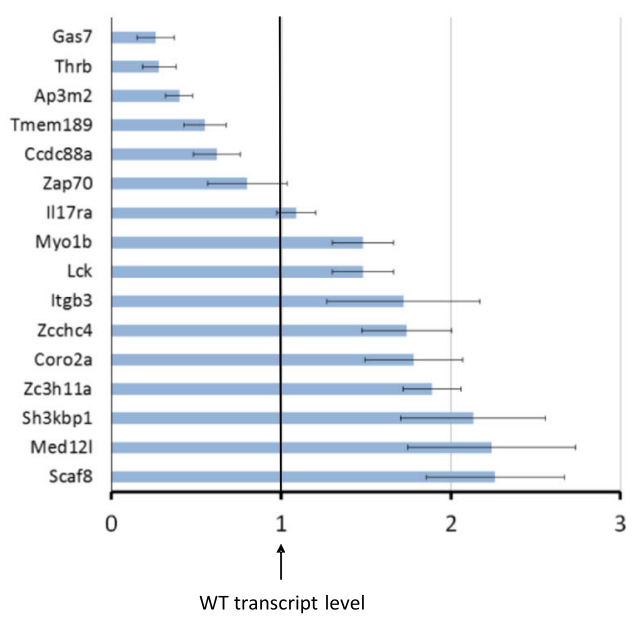

Fig. 5 Gene regulation by nuclear WASp ${ }^{1296 T}$. a Functional groups of peak-corresponding genes in WASp ChIP-seq refined datasets. b Gene expression profiling by RT-qPCR of WASp ${ }^{1296 T}$ ChIP-seq genes in WASp ${ }^{1266 T}$ vs. WT thymocytes. Expression in WASp ${ }^{1296 T}$ thymocytes is shown and compared with expression in WT thymocytes set to 1. Gene expression profiling by RT-qPCR was performed in three biological replicates: WASp $^{1296 T} n=3$ vs. WT $n=3$ and in three technical replicates for each cDNA template sample with Ct variation between triplicates less than cut-off \pm 0.25 . Resulted gene expression data: the mean of the technical triplicate, $\Delta C t, R Q$ value, and standard deviation between $R Q$ of biological triplicates is indicated. Additional file 3: sheet 3 


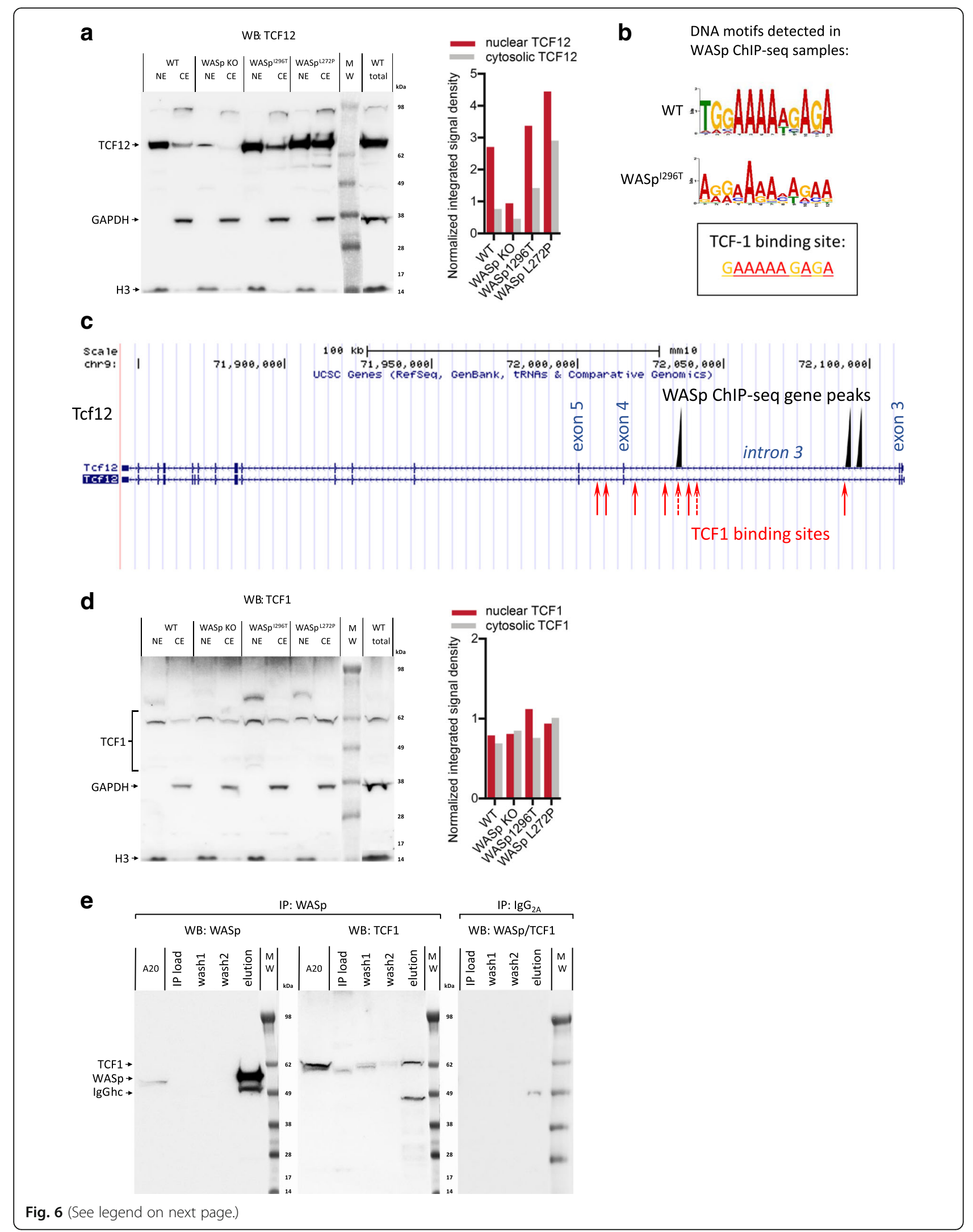




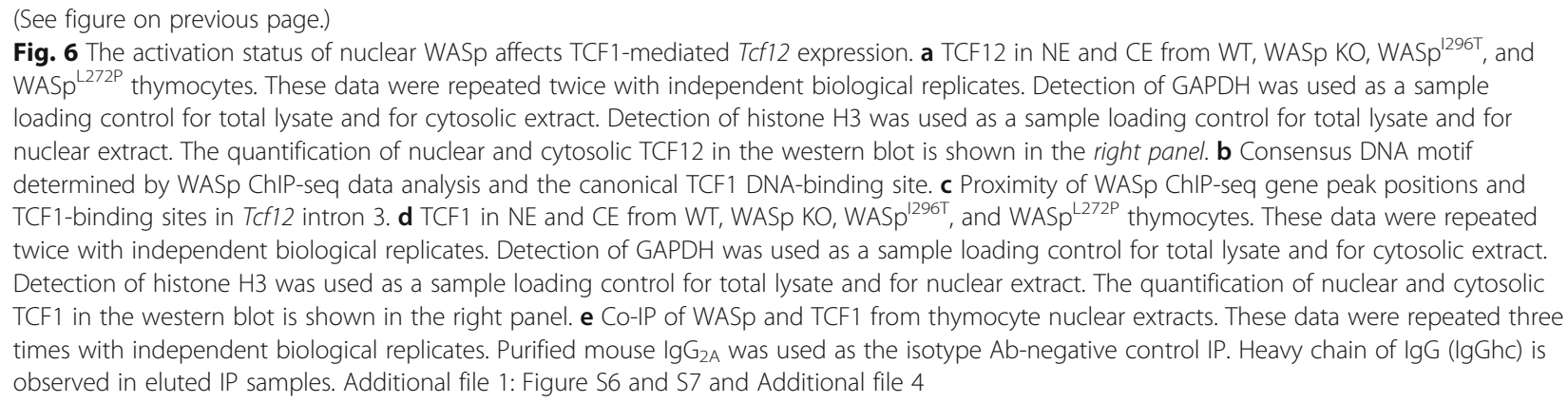

Interestingly, WASp-interacting sequences in WT thymocytes were enriched for a DNA element identical to the TCF1-binding site (Fig. 6b) [47]. WASp ${ }^{\text {I296T }}$-interacting sequences from thymocytes were also enriched for at DNA element with similarity to the TCF1-binding site (Fig. 6b). We next examined if the Tcf12 gene contained TCF1-binding sites. We identified several TCF1-binding sites in Tcf12 introns 3 and 4 in close proximity to the WASp-enriched sequences (Fig. 6c, Additional file 1: Figure S6A). To examine TCF1 protein in nuclear and cytosolic extracts from WT, WASp KO, WASp ${ }^{\mathrm{L} 272 \mathrm{P}}$, and WASp $^{\text {I296T }}$ thymocytes, we used an Ab that is specific for the longest TCF1 isoform that is transcriptionally active due to its binding to $\beta$-catenin $[50,51]$. TCF1 was detected in all lysates with predominant localization in the nuclear extracts (Fig. 6d). To determine if WASp directly interacted with TCF1, WASp was immunoprecipitated from thymocyte nuclear extracts using the WASp F-8 Ab and found to co-immunoprecipitate with TCF1 (Fig. 6e). This suggests that WASp and TCF1 may interact to drive transcription of TCF1 pathway genes including $T c f 1$ itself. In support of this, the WASp ChIPseq dataset identified several WASp-interacting genes that are induced by TCF1 signaling (Additional file 1 : Figure S6B). Together, these data suggest that nuclear WASp acts in close proximity with TCF1 and TCF12 (see tentative model in Additional file 1: Figure S7).

\section{Discussion}

The contribution of nuclear WASp activity for T cell development remains incompletely defined. Using genome-wide analysis of the global genome occupancy of WASp in T cells, we found that WASp interacted with both intergenic and genic sequences and was enriched at TSSs of a large number of protein-coding genes. In the absence of WASp, RNA polymerase II transcription was reduced, suggesting that WASp participates in regulation of basal RNA polymerase II transcription. We identified that WASp-enriched sequences had a consensus-binding site identical to the TCF1binding site and that WASp interacted with TCF1 in the nucleus. Moreover, we show that WASp interacted with promoter-proximal introns of the gene encoding TCF12 and that the activation status of WASp influenced the level of TCF12 protein in the nucleus.

WASp-enriched genes in thymus and spleen $\mathrm{CD}^{+}{ }^{+} \mathrm{T}$ cell samples shared similar features in regard to functional groups and intragenic and genic occupancy. In thymocytes, we found a large fraction of WASp in the nuclear fraction when compared to the cytosolic fraction. This was in contrast to spleen $\mathrm{CD}^{+}{ }^{+} \mathrm{T}$ cells where much less WASp was present in the nuclear fraction. This suggests that the nuclear activity of WASp is important during thymocyte development. In spleen $\mathrm{CD}^{+}$ T cells, the cytosolic activity of WASp in engaging proximal $\mathrm{T}$ cell receptor signaling may become more important as shown in many studies [18]. We identified some common genes when comparing global gene occupancy by WASp in thymocytes and spleen $\mathrm{CD}^{+} \mathrm{T}$ cells (our datasets) with the targeted ChIP on array approach for genes that regulate Th1 and Th2 commitment [38, 39]. Among common WASp ChIP-seq enriched genes were a mouse orthologue Mamld1 of previously reported Mastermind like1 (MAML1) as well as other genes involved in Notch signaling pathways including in thymocytes Sbno2 and in spleen CD4 ${ }^{+}$T cells cadherin- 6 and Rbpj. We observed a number of regulatory genes associated with histone acetylation and deacetylation activities including in thymocytes Kat6b (histone acetyltransferase KAT6B) and in spleen CD4 ${ }^{+}$T cells Kansl1 (KAT8 regulatory NSL complex subunit 1), Sirt6 (NAD-dependent protein deacetylase sirtuin-6), and Hdac8 (histone deacetylase 8). Previously identified genes such as Foxp3 and Tbx1 [38, 39] were not found in our datasets.

The signature of the WASp-enriched genes suggested that WASp serves a role both in basal RNA polymerase II transcription and in regulation of specific genes. Although basal RNA Polymerase II gene transcription was lower in WASp KO thymocytes, we identified a few exceptions where expression of specific genes was upregulated in WASp $\mathrm{KO}$ thymocytes. When comparing WASp-enriched genes in thymocytes and spleen $\mathrm{CD}^{+}$ $\mathrm{T}$ cells we found 15 common genes. Several of these genes showed lower expression in WASp KO 
thymocytes including Vav2 and Vav3 that coordinate proximal $\mathrm{T}$ cell receptor signaling to activation of the Rho GTPases Rac1, Rac2, and Cdc42 and WASp family members. Five of the 15 common WASp-enriched genes were upregulated in WASp KO thymocytes. Of these, WASp interaction with $N f a t c 2$ is interesting since it suggests that nuclear WASp may regulate $N f a t c 2$ expression and thereby production of interleukin-2. WASp KO T cells have reduced translocation of Nfatc 2 into the nucleus upon $\mathrm{T}$ cell receptor stimulation [30] and we show here that this may be compensated by increased expression of Nfatc2 in WASp KO thymocytes. WASf2, that encodes for WASp family member WAVE2 also showed increased expression in WASp KO thymocytes, suggesting that loss of WASp stimulated transcription of WAVE2. The WASp family members are known to be able to compensate for each other to support actin polymerization. N-WASp can compensate for loss of WASp in development and function of $\mathrm{B}$ and $\mathrm{T}$ cells $[21,52-54]$. However, the compensation is not complete as evident in increased frequency of autoreactive B and T cells that only express N-WASp [20, 53-55]. Our data provide an example where this cross-compensation between WASp family members may occur in the nucleus through interaction of WASp with WASf2 and increased gene expression of WASf2 in WASp KO cells.

Several WASp family members are present in the nucleus and it is feasible to assume, based on their activity in the cytoplasm, that they at least in part may exert function in the open conformation exposing their VCA domain. We provide evidence for that the active open conformation of WASp in WASp ${ }^{\text {L272P }}$ and WASp ${ }^{\text {I296T }}$ thymocytes showed same intensity of basal gene transcription when compared to WT thymocytes, and had higher expression of specific genes. Moreover, WASp $^{\text {L272P }}$ and WASp ${ }^{\text {I296T }}$ thymocytes had more nuclear TCF12 protein when compared to WT thymocytes, perhaps indicating that a fraction of WT WASp resides in an autoinhibited conformation that prevents overactivation of WASp. Previous data suggest that gene transcription regulated by a WASp family member can be both dependent and independent on the VCA domain. In human $\mathrm{T}$ cells differentiated into Th1 cells, the WASp-VCA domain is dispensable for gene transcription of Tbx12-target genes [56]. Instead, sumoylation of WASp at lysine residues is important for transcription of this set of genes [57]. In Xenopus oocytes, WAVE1induced gene transcription and reprogramming is independent of the WAVE1 VCA-like domain [58]. There are also examples of WASp family members that require the VCA domain and actin for gene transcription. In HeLa cell nuclei, N-WASP is part of a large nuclearprotein complex containing polypyrimidine-tractbinding-protein-associated splicing factor-non-Pou- domain octamer-binding protein/p54nrb (PSF-NonO), nuclear actin, and RNA polymerase II [59]. The PSFNonO complex is involved in the regulation of many cellular processes, such as transcription, RNA processing, DNA unwinding, and repair. Interestingly, an NWASPAVCA mutant localizes within the nucleus but is defective in actin polymerization resulting in significantly decreased gene transcription [59]. WASH is located in the nucleus of hematopoietic stem cells where it associates with the nucleosome remodeling factor (NURF) complex and assists the NURF complex to the promoter of the $c-M y c$ gene necessary for hematopoietic stem cell differentiation [60]. The nuclear activity of WASH is dependent on nuclear actin polymerization induced by the WASH VCA domain [60]. Together, these studies raise the possibility that the multiple domains of WASp family members may have unique biological functions in the nucleus and that nuclear activity is regulated by the VCA domain as well as other functional domains similar to the role of WASp family members in the cytoplasm. In vitro, dimers or oligomers of WASp family VCA domains bind with 100-fold higher affinity to Arp2/3 when compared to monomers of VCA domains [61]. This suggests that homo- and heterodimerization of active WASp provides an additional layer of regulation beyond conformation and functional domains. Our data lend evidence to the open conformation of WASp being required for global gene occupancy and that constitutively active WASp in WASp ${ }^{\text {L272P }}$ and WASp ${ }^{\text {I296T }}$ thymocytes induced increased transcription of specific genes including Tcf12.

Here we identify that WASp targeted genes were enriched for a DNA-binding site identical to the TCF1binding site. TCF1 is one of the earliest transcriptional regulators induced in thymus and essential for $\mathrm{T}$ cell commitment [62-64]. TCF1 is most abundant in CD4 ${ }^{+} \mathrm{CD}^{+}$double-positive thymocytes and its absence compromises $\mathrm{CD}^{+} \mathrm{CD}^{+}$thymocyte survival $[65,66]$. TCF1 constitutively interacts with DNA and mediates repression of gene transcription when bound to Groucho and activation of transcription when bound to $\beta$-catenin [67-69]. Bioinformatic analysis suggests that WASp lacked DNA-binding properties. Instead, WASp interacted with TCF1 leading to transcription of a subset of target genes downstream of TCF1. This indicates that WASp in complex with TCF1 may regulate transcription of a subset of some but not all TCF1 pathway genes. This suggests that the WASp-TCF1 interaction may be complex and modulated by other binding partners and/ or modulators of transcription. Deletion of TCF1 specifically in $\mathrm{CD} 4{ }^{+} \mathrm{CD} 8{ }^{+}$double-positive thymocytes leads to a skewed CD4/CD8 ratio with increased number of CD8 ${ }^{+} \mathrm{T}$ cells [70]. Despite the reduction in basal RNA Polymerase II transcription and TCF1 pathway genes such as 
Tcf12, WASp KO thymocytes develop normally in regard to number of $\mathrm{CD}^{+}$and $\mathrm{CD} 8^{+}$single-positive thymocytes [21]. However, WASp KO mice have decreased $\mathrm{CD} 4 / \mathrm{CD} 8 \mathrm{~T}$ cell ratio in peripheral organs, leading to increased accumulation of $\mathrm{CD}^{+} \mathrm{T}$ cells in skin, spleen, and lymph nodes [71]. Moreover, WASp-deficient thymocytes and $\mathrm{T}$ cells have reduced capacity to respond to $\mathrm{T}$ cell receptor stimulation [21, 28-30]. Therefore, it is not surprising that an increasing number of reports have identified aberrations in $\mathrm{T}$ cell development and differentiation in WASp deficiency including an oligoclonal $\mathrm{T}$ cell receptor repertoire often found in autoreactive $\mathrm{T}$ cells [23-27], increased number of $\mathrm{CD}_{4} 4^{+} \mathrm{CD} 62 \mathrm{~L}^{-}$effector memory $\mathrm{T}$ cells $[21,71]$, and $\mathrm{T}$ cell-driven autoimmune colitis [20-22, 72]. Early studies of postmortem examination of WAS patients showed thymic hypoplasia [73], suggesting reduced thymic function and $T$ cell development. A reduction in peripheral blood $\mathrm{T}$ cell number is apparent already at an early age in WAS patient and older patients have marked $\mathrm{T}$ cell lymphopenia [7476]. Together, this suggests that WASp deficiency leads to aberrant $\mathrm{T}$ cell development and that thymocytes have reduced capacity to undergo central tolerance checkpoint to delete autoreactive $\mathrm{T}$ cells. The data presented here support this idea by showing that the nuclear activity of WASp is important to regulate gene transcription in a transcriptional network with TCF1 and TCF12 during $\mathrm{T}$ cell development. Constitutive activation of the $\beta$ catenin-TCF1 pathway is associated with genomic instability and T cell lymphomas $[77,78]$. Future studies of nuclear WASp may reveal whether dysregulation of $\beta$ catenin-TCF1 signaling is associated with increased frequency of lymphoma in WAS patients.

\section{Conclusions}

To identify the global genome occupancy of WASp, we have used ChIP-seq for WASp in thymocytes and spleen $\mathrm{CD}^{+}{ }^{+} \mathrm{T}$ cells. We found that WASp interacted with coding and non-coding DNA regions and that WASp deficiency resulted in decreased RNA polymerase II transcription. Finally, we identified a molecular network important for T cell development placing nuclear WASp in close proximity with TCF1 and TCF12.

\section{Additional files}

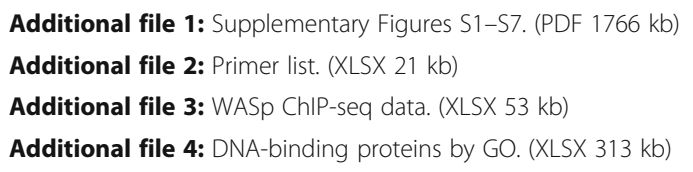

\section{Abbreviations}

Ab: Antibody; Arp: Actin-related protein; ChIP-seq: Chromatin

immunoprecipitation and deep sequencing; FUrd: Fluorine-conjugated UTP;
HEB: HeLa E-box-binding protein; IP: Immunoprecipitation; JMY: Junctionmediating and regulatory protein; Lef: Lymphoid enhancer factor; Nfatc: Nuclear factor of activated T cells; SCAR: Suppressor of the cyclic AMP receptor; SWI/SNF: SWItch/Sucrose Non-Fermentable complexes; TCF: T cell factor; TCR: T cell receptor; Th: T helper; TSS: Transcriptional start site; VCA: Verprolin cofilin acidic; WASH: WASp and SCAR homologue; WASp: Wiskott-Aldrich syndrome protein; WAVE: WASp-family verprolinhomologous protein; WT: Wild type; XLN: X-linked neutropenia

\section{Acknowledgements}

We wish to acknowledge the valuable technical assistance from Dr Anna Kouznetsova (Karolinska Institutet) and Amgen scholar students Wenqing Yan, Yi Fei Lee, and Pei Yee Tey. We would like to thank BGl (Shenzhen, Guangdong, China) for providing the excellent service.

\section{Funding}

This work was supported by PhD fellowships from Fundação para a Ciência e a Tecnologia to MAPB and MMSO, a PhD fellowship from NGHA-KAIMRC Saudi Arabia to BA, a PhD fellowship from Karolinska Institutet to MMSO, a postdoctoral fellowship from Cancer Society to MK; research grants from the Swedish Research Council and Cancer Society to PP and LSW, as well as research grants from Childhood Cancer Society, the European Commission 7th framework program Marie Curie Reintegration Grant (\#249177), Karolinska Institutet, Åke Olsson Foundation, Jeansson Foundation, Groschinsky Foundation, Åke Wiberg Foundation, Bergvall Foundation, King Gustaf V's 80-year Foundation, and the Swedish Medical Society to LSW. LSW is a Ragnar Söderberg fellow in Medicine.

\section{Availability of data and materials}

The datasets supporting the conclusions of this article are deposited at the GEO repository: https://www.ncbi.nlm.nih.gov/geo/query/

acc.cgi?token=gjopqyeitlglnmt\&acc=GSE89172 and shown in Additional files 1,2 , and 3.

\section{Authors' contributions}

NVK and LSW designed the research; NVK, BA, JK, MAPB, MK, and MMSO performed the research; SBS contributed with new analytic tools; NVK, BA, JK, MAPB, MMSO, MK, PP, and LSW analyzed data; NVK and LSW wrote the manuscripts and all authors edited the manuscript.

\section{Ethics approval}

Animal experimentation: animals were housed in a specific pathogen-free environment in the animal facility of the Department of Microbiology, Tumor and Cell Biology at Karolinska Institutet under specific pathogen-free conditions; all experiments conformed to the ethical principles and guidelines approved by the local ethical committee (the north Stockholm district court); protocol approval number: N77/13.

\section{Consent for publication}

This study does not involve human subjects and individual consent for publication is not applicable.

\section{Competing interests}

The authors declare that they have no competing interests.

\section{Publisher's Note}

Springer Nature remains neutral with regard to jurisdictional claims in published maps and institutional affiliations.

\section{Author details}

${ }^{1}$ Department of Microbiology Tumor and Cell biology, Karolinska Institutet, Stockholm 171 77, Sweden. 'Department of Cell and Molecular Biology, Karolinska Institutet, Stockholm 171 77, Sweden. ${ }^{3}$ King Abdullah International Medical Research Center/King Saud bin Abdulaziz University for Health Sciences Medical Genomic Research Department, MNGHA, Riyadh, Saudi Arabia. ${ }^{4}$ Institute for Virology and Immunobiology, University of Würzburg, 97078 Würzburg, Germany. ${ }^{5}$ Gastroenterology Division, Children's Hospital, Harvard Medical School, Boston, MA 02115, USA. 'Biology Program, New York University Abu Dhabi (NYUAD), P.O. Box 129188, Abu Dhabi, United Arab Emirates. ${ }^{7}$ Department of Molecular Biosciences, The Wenner-Gren Institute, Stockholm University, 10691 Stockholm, Sweden. 
Received: 19 July 2017 Accepted: 11 October 2017

Published online: 27 October 2017

\section{References}

1. Grosse R, Vartiainen MK. To be or not to be assembled: progressing into nuclear actin filaments. Nat Rev Mol Cell Biol. 2013;14(11):693-7.

2. Almuzzaini B, Sarshad AA, Farrants AK, Percipalle P. Nuclear myosin 1 contributes to a chromatin landscape compatible with RNA polymerase II transcription activation. BMC Biol. 2015;13:35.

3. Sarshad A, Sadeghifar F, Louvet E, Mori R, Bohm S, Al-Muzzaini B, et al. Nuclear myosin 1c facilitates the chromatin modifications required to activate rRNA gene transcription and cell cycle progression. PLoS Genet. 2013:9(3):e1003397.

4. Sarshad AA, Corcoran M, Al-Muzzaini B, Borgonovo-Brandter L, Von Euler A, Lamont D, et al. Glycogen synthase kinase (GSK) 3beta phosphorylates and protects nuclear myosin 1c from proteasome-mediated degradation to activate rDNA transcription in early G1 cells. PLoS Genet. 2014;10(6): e1004390.

5. Kapoor $P$, Chen M, Winkler DD, Luger $K$, Shen X. Evidence for monomeric actin function in INO80 chromatin remodeling. Nat Struct Mol Biol. 2013; 20(4):426-32.

6. Campellone KG, Welch MD. A nucleator arms race: cellular control of actin assembly. Nat Rev Mol Cell Biol. 2010;11(4):237-51.

7. Moulding DA, Record J, Malinova D, Thrasher AJ. Actin cytoskeletal defects in immunodeficiency. Immunol Rev. 2013;256(1):282-99.

8. Kim AS, Kakalis LT, Abdul-Manan N, Liu GA, Rosen MK. Autoinhibition and activation mechanisms of the Wiskott-Aldrich syndrome protein. Nature. 2000;404(6774):151-8.

9. Torres E, Rosen MK. Contingent phosphorylation/dephosphorylation provides a mechanism of molecular memory in WASP. Mol Cell. 2003;11(5): 1215-27.

10. Rohatgi R, Ma L, Miki H, Lopez M, Kirchhausen T, Takenawa T, et al. The interaction between N-WASP and the Arp2/3 complex links Cdc42dependent signals to actin assembly. Cell. 1999;97(2):221-31.

11. Machesky LM, Insall RH. Scar1 and the related Wiskott-Aldrich syndrome protein, WASP, regulate the actin cytoskeleton through the Arp2/3 complex. Curr Biol. 1998:8(25):1347-56.

12. Miki H, Suetsugu S, Takenawa T. WAVE, a novel WASP-family protein involved in actin reorganization induced by Rac. EMBO J. 1998:17(23):6932-41.

13. Eden S, Rohatgi R, Podtelejnikov AV, Mann M, Kirschner MW. Mechanism of regulation of WAVE1-induced actin nucleation by Rac1 and Nck. Nature. 2002;418(6899):790-3.

14. Dustin ML. What counts in the immunological synapse? Mol Cell. 2014;54(2): 255-62.

15. Rothenberg EV. Transcriptional drivers of the T-cell lineage program. Curr Opin Immunol. 2012;24(2):132-8.

16. Braunstein M, Anderson MK. HEB in the spotlight: transcriptional regulation of T-cell specification, commitment, and developmental plasticity. Clin Dev Immunol. 2012;2012:678705.

17. Massaad MJ, Ramesh N, Geha RS. Wiskott-Aldrich syndrome: a comprehensive review. Ann N Y Acad Sci. 2013;1285:26-43.

18. Thrasher AJ, Burns SO. WASP: a key immunological multitasker. Nat Rev Immunol. 2010;10(3):182-92.

19. Catucci M, Castiello MC, Pala F, Bosticardo M, Villa A. Autoimmunity in wiskott-Aldrich syndrome: an unsolved enigma. Front Immunol. 2012;3:209.

20. Nguyen DD, Maillard MH, Cotta-de-Almeida V, Mizoguchi E, Klein C, Fuss I, et al. Lymphocyte-dependent and Th2 cytokine-associated colitis in mice deficient in Wiskott-Aldrich syndrome protein. Gastroenterology. 2007; 133(4):1188-97.

21. Cotta-de-Almeida V, Westerberg L, Maillard MH, Onaldi D, Wachtel H, Meelu $P$, et al. Wiskott Aldrich syndrome protein (WASP) and N-WASP are critical for T cell development. Proc Natl Acad Sci U S A. 2007;104(39):15424-9.

22. Nguyen DD, Wurbel MA, Goettel JA, Eston MA, Ahmed OS, Marin R, et al. Wiskott-Aldrich syndrome protein deficiency in innate immune cells leads to mucosal immune dysregulation and colitis in mice. Gastroenterology. 2012;143:719-29.

23. O'Connell AE, Volpi S, Dobbs K, Fiorini C, Tsitsikov E, de Boer $\mathrm{H}$, et al. Next generation sequencing reveals skewing of the $T$ and $B$ cell receptor repertoires in patients with wiskott-Aldrich syndrome. Front Immunol. 2014;5:340.
24. Wada T, Schurman SH, Garabedian EK, Yachie A, Candotti F. Analysis of T-cell repertoire diversity in Wiskott-Aldrich syndrome. Blood. 2005;106(12):3895-7.

25. Braun CJ, Boztug K, Paruzynski A, Witzel M, Schwarzer A, Rothe M, et al. Gene therapy for Wiskott-Aldrich syndrome-long-term efficacy and genotoxicity. Sci Transl Med. 2014;6:227ra33.

26. Wu J, Liu D, Tu W, Song W, Zhao X. T-cell receptor diversity is selectively skewed in T-cell populations of patients with Wiskott-Aldrich syndrome. J Allergy Clin Immunol. 2015;135(1):209-16.

27. Petersen SH, Sendel A, van der Burg M, Westerberg LS. Unraveling the repertoire in wiskott-Aldrich syndrome. Front Immunol. 2014;5:539.

28. Snapper SB, Rosen FS. The Wiskott-Aldrich syndrome protein (WASP): roles in signaling and cytoskeletal organization. Annu Rev Immunol. 1999;17:905-29.

29. Zhang J, Shehabeldin A, da Cruz LA, Butler J, Somani AK, McGavin M, et al. Antigen receptor-induced activation and cytoskeletal rearrangement are impaired in Wiskott-Aldrich syndrome protein-deficient lymphocytes. J Exp Med. 1999;190(9):1329-42.

30. Cianferoni A, Massaad M, Feske S, de la Fuente MA, Gallego L, Ramesh N, et al. Defective nuclear translocation of nuclear factor of activated T cells and extracellular signal-regulated kinase underlies deficient IL-2 gene expression in Wiskott-Aldrich syndrome. J Allergy Clin Immunol. 2005;116(6):1364-71.

31. Silvin C, Belisle B, Abo A. A role for Wiskott-Aldrich syndrome protein in Tcell receptor-mediated transcriptional activation independent of actin polymerization. J Biol Chem. 2001;276(24):21450-7.

32. Huang W, Ochs HD, Dupont B, Vyas YM. The Wiskott-Aldrich syndrome protein regulates nuclear translocation of NFAT2 and NF-kappa B (RelA) independently of its role in filamentous actin polymerization and actin cytoskeletal rearrangement. J Immunol. 2005;174(5):2602-11.

33. Moulding DA, Blundell MP, Spiller DG, White MR, Cory GO, Calle Y, et al. Unregulated actin polymerization by WASp causes defects of mitosis and cytokinesis in X-linked neutropenia. J Exp Med. 2007;204(9):2213-24.

34. Ancliff PJ, Blundell MP, Cory GO, Calle Y, Worth A, Kempski H, et al. Two novel activating mutations in the Wiskott-Aldrich syndrome protein result in congenital neutropenia. Blood. 2006;108(7):2182-9.

35. Devriendt K, Kim AS, Mathijs G, Frints SG, Schwartz M, Van Den Oord J, Jes et al. Constitutively activating mutation in WASP causes $X$-linked severe congenital neutropenia. Nat Genet. 2001;27(3):313-7.

36. Beel K, Cotter MM, Blatny J, Bond J, Lucas G, Green F, et al. A large kindred with X-linked neutropenia with an 1294T mutation of the Wiskott-Aldrich syndrome gene. Br J Haematol. 2009;144(1):120-6.

37. Westerberg LS, Meelu P, Baptista M, Eston MA, Adamovich DA, Cotta-de-Almeida $V$, et al. Activating WASP mutations associated with X-linked neutropenia result in enhanced actin polymerization, altered cytoskeletal responses, and genomic instability in lymphocytes. J Exp Med. 2010;207(6):1145-52.

38. Taylor MD, Sadhukhan S, Kottangada P, Ramgopal A, Sarkar K, D'Silva S, et al. Nuclear role of WASp in the pathogenesis of dysregulated TH1 immunity in human Wiskott-Aldrich syndrome. Sci Transl Med. 2010;2:37ra44.

39. Sarkar K, Sadhukhan S, Han SS, Vyas YM. Disruption of hSWI/SNF complexes in T cells by WAS mutations distinguishes $X$-linked thrombocytopenia from Wiskott-Aldrich syndrome. Blood. 2014;124(23):3409-19.

40. Snapper SB, Rosen FS, Mizoguchi E, Cohen P, Khan W, Liu CH, et al. WiskottAldrich syndrome protein-deficient mice reveal a role for WASP in T but not B cell activation. Immunity. 1998;9(1):81-91.

41. Percipalle $P$, Louvet $E$. In vivo run-on assays to monitor nascent precursor RNA transcripts. Methods Mol Biol. 2012;809:519-33.

42. Zhang Y, Liu T, Meyer CA, Eeckhoute J, Johnson DS, Bernstein BE, et al. Model-based analysis of ChIP-Seq (MACS). Genome Biol. 2008;9(9):R137.

43. Zang C, Schones DE, Zeng C, Cui K, Zhao K, Peng W. A clustering approach for identification of enriched domains from histone modification ChIP-Seq data. Bioinformatics. 2009;25(15):1952-8.

44. Kidder BL, Hu G, Zhao K. ChIP-Seq: technical considerations for obtaining high-quality data. Nat Immunol. 2011;12(10):918-22.

45. Shao Z, Zhang Y, Yuan GC, Orkin SH, Waxman DJ. MAnorm: a robust model for quantitative comparison of ChIP-Seq data sets. Genome Biol. 2012;13(3):R16.

46. Chen TW, Li HP, Lee CC, Gan RC, Huang PJ, Wu TH, et al. ChIPseek, a webbased analysis tool for ChIP data. BMC Genomics. 2014;15:539.

47. Matys V, Kel-Margoulis OV, Fricke E, Liebich I, Land S, Barre-Dirrie A, et al. TRANSFAC and its module TRANSCompel: transcriptional gene regulation in eukaryotes. Nucleic Acids Res. 2006:34(Database issue):D108-10.

48. Peric-Hupkes D, Meuleman W, Pagie L, Bruggeman SW, Solovei I, Brugman $W$, et al. Molecular maps of the reorganization of genome-nuclear lamina interactions during differentiation. Mol Cell. 2010;38(4):603-13. 
49. Obrdlik A, Kukalev A, Louvet E, Farrants AK, Caputo L, Percipalle P. The histone acetyltransferase PCAF associates with actin and hnRNP $U$ for RNA polymerase II transcription. Mol Cell Biol. 2008;28(20):6342-57.

50. Xu Z, Xing S, Shan Q, Gullicksrud JA, Bair TB, Du Y, et al. Cutting edge: betacatenin-interacting Tff1 isoforms are essential for thymocyte survival but dispensable for thymic maturation transitions. J Immunol. 2017;198(9):3404-9.

51. Gullicksrud JA, Li F, Xing S, Zeng Z, Peng W, Badovinac VP, et al. Differential requirements for Tcf1 long isoforms in CD8+ and CD4+ T cell responses to acute viral infection. J Immunol. 2017;199(3):911-9.

52. Westerberg LS, Dahlberg C, Baptista M, Moran CJ, Detre C, Keszei M, et al. Wiskott-Aldrich syndrome protein (WASP) and N-WASP are critical for peripheral B-cell development and function. Blood. 2012;119(17):3966-74.

53. Dahlberg $\mathrm{Cl}$, Torres ML, Petersen SH, Baptista MA, Keszei M, Volpi S, et al. Deletion of WASp and N-WASp in B cells cripples the germinal center response and results in production of IgM autoantibodies. J Autoimmun. 2015;62:81-92

54. Volpi S, Santori E, Abernethy K, Mizui M, Dahlberg Cl, Recher M, et al. NWASP is required for B-cell-mediated autoimmunity in Wiskott-Aldrich syndrome. Blood. 2016;127(2):216-20.

55. Liu C, Bai X, Wu J, Sharma S, Upadhyaya A, Dahlberg Cl, et al. N-wasp is essential for the negative regulation of $B$ cell receptor signaling. PLoS Biol. 2013;11(11):e1001704.

56. Sadhukhan S, Sarkar K, Taylor M, Candotti F, Vyas YM. Nuclear role of WASp in gene transcription is uncoupled from its ARP2/3-dependent cytoplasmic role in actin polymerization. J Immunol. 2014;193(1):150-60.

57. Sarkar K, Sadhukhan S, Han SS, Vyas YM. SUMOylation-disrupting WAS mutation converts WASp from a transcriptional activator to a repressor of NF-kappaB response genes in T cells. Blood. 2015;126(14):1670-82.

58. Miyamoto K, Teperek M, Yusa K, Allen GE, Bradshaw CR, Gurdon JB. Nuclear Wave 1 is required for reprogramming transcription in oocytes and for normal development. Science. 2013;341(6149):1002-5.

59. Wu X, Yoo Y, Okuhama NN, Tucker PW, Liu G, Guan JL. Regulation of RNApolymerase-II-dependent transcription by N-WASP and its nuclear-binding partners. Nat Cell Biol. 2006;8(7):756-63.

60. Xia P, Wang S, Huang G, Zhu P, Li M, Ye B, et al. WASH is required for the differentiation commitment of hematopoietic stem cells in a c-Mycdependent manner. J Exp Med. 2014;211(10):2119-34.

61. Padrick SB, Cheng HC, Ismail AM, Panchal SC, Doolittle LK, Kim S, et al. Hierarchical regulation of WASP/WAVE proteins. Mol Cell. 2008;32(3):426-38.

62. Germar K, Dose M, Konstantinou T, Zhang J, Wang H, Lobry C, et al. T-cell factor 1 is a gatekeeper for T-cell specification in response to notch signaling. Proc Natl Acad Sci U S A. 2011;108(50):20060-5.

63. Weber BN, Chi AW, Chavez A, Yashiro-Ohtani Y, Yang Q, Shestova O, et al. A critical role for TCF-1 in T-lineage specification and differentiation. Nature. 2011;476(7358):63-8.

64. Verbeek S, Izon D, Hofhuis F, Robanus-Maandag E, te Riele H, van de Wetering $\mathrm{M}$, et al. An HMG-box-containing T-cell factor required for thymocyte differentiation. Nature. 1995;374(6517):70-4.

65. Wang $R$, Xie $H$, Huang $Z$, Ma J, Fang $X$, Ding $Y$, et al. T cell factor 1 regulates thymocyte survival via a RORgammat-dependent pathway. J Immunol. 2011; 187(11):5964-73.

66. Ioannidis V, Beermann F, Clevers H, Held W. The beta-catenin-TCF-1 pathway ensures CD4(+)CD8(+) thymocyte survival. Nat Immunol. 2001;2(8):691-7.

67. Brantjes $H$, Roose J, van De Wetering M, Clevers H. All Tcf HMG box transcription factors interact with groucho-related co-repressors. Nucleic Acids Res. 2001;29:1410-9.

68. Xie H, Huang Z, Sadim MS, Sun Z. Stabilized beta-catenin extends thymocyte survival by up-regulating BCl-XL. J Immunol. 2005;175(12):7981-8.

69. Goux D, Coudert JD, Maurice D, Scarpellino L, Jeannet G, Piccolo S, et al Cooperating pre-T-cell receptor and TCF-1-dependent signals ensure thymocyte survival. Blood. 2005;106(5):1726-33.

70. Steinke FC, Yu S, Zhou X, He B, Yang W, Zhou B, et al. TCF-1 and LEF-1 act upstream of Th-POK to promote the CD4(+) T cell fate and interact with Runx3 to silence Cd4 in CD8(+) T cells. Nat Immunol. 2014;15(7):646-56.

71. Baptista MA, Keszei M, Oliveira M, Sunahara KK, Andersson J, Dahlberg Cl, et al. Deletion of Wiskott-Aldrich syndrome protein triggers Rac2 activity and increased cross-presentation by dendritic cells. Nat Commun. 2016;7:12175.

72. Maillard MH, Cotta-de-Almeida V, Takeshima F, Nguyen DD, Michetti $\mathrm{P}$, Nagler $C$, et al. The Wiskott-Aldrich syndrome protein is required for the function of CD4(+)CD25(+)Foxp3(+) regulatory T cells. J Exp Med. 2007; 204(2):381-91.
73. Wolff JA. Wiskott-Aldrich syndrome: clinical, immunologic, and pathologic observations. J Pediatr. 1967;70(2):221-32.

74. Park JY, Kob M, Prodeus AP, Rosen FS, Shcherbina A, Remold-O'Donnell E. Early deficit of lymphocytes in Wiskott-Aldrich syndrome: possible role of WASP in human Iymphocyte maturation. Clin Exp Immunol. 2004;136(1):104-10.

75. Ochs HD, Slichter SJ, Harker LA, Von Behrens WE, Clark RA, Wedgwood RJ. The Wiskott-Aldrich syndrome: studies of lymphocytes, granulocytes, and platelets. Blood. 1980;55(2):243-52.

76. Zhang X, Dai R, Li W, Zhao H, Zhang Y, Zhou L, et al. Abnormalities of follicular helper T-cell number and function in Wiskott-Aldrich syndrome. Blood. 2016;127(25):3180-91.

77. Dose M, Emmanuel AO, Chaumeil J, Zhang J, Sun T, Germar K, et al. betaCatenin induces T-cell transformation by promoting genomic instability. Proc Natl Acad Sci U S A. 2014;111(1):391-6.

78. Guo Z, Dose M, Kovalovsky D, Chang R, O'Neil J, Look AT, et al. Beta-catenin stabilization stalls the transition from double-positive to single-positive stage and predisposes thymocytes to malignant transformation. Blood. 2007;109(12):5463-72.

\section{Submit your next manuscript to BioMed Central and we will help you at every step:}

- We accept pre-submission inquiries

- Our selector tool helps you to find the most relevant journal

- We provide round the clock customer support

- Convenient online submission

- Thorough peer review

- Inclusion in PubMed and all major indexing services

- Maximum visibility for your research

Submit your manuscript at www.biomedcentral.com/submit
) Biomed Central 